\title{
The spatiotemporal variation and control mechanism of surface pCO2 in winter in Jiaozhou Bay, China
}

Article

Accepted Version

Creative Commons: Attribution-Noncommercial-No Derivative Works 4.0

Li, Y., Yang, H. ORCID: https://orcid.org/0000-0001-99408273, Zhang, L., Yang, X., Zang, H., Fan, W. and Wang, G. (2020) The spatiotemporal variation and control mechanism of surface pCO2 in winter in Jiaozhou Bay, China. Continental Shelf Research, 206. 104208. ISSN 0278-4343 doi: https://doi.org/10.1016/j.csr.2020.104208 Available at https://centaur.reading.ac.uk/95935/

It is advisable to refer to the publisher's version if you intend to cite from the work. See Guidance on citing.

Published version at: https://www.sciencedirect.com/science/article/pii/S0278434320301631

To link to this article DOI: http://dx.doi.org/10.1016/j.csr.2020.104208

Publisher: Elsevier

All outputs in CentAUR are protected by Intellectual Property Rights law, including copyright law. Copyright and IPR is retained by the creators or other copyright holders. Terms and conditions for use of this material are defined in the End User Agreement. 


\section{CentAUR}

Central Archive at the University of Reading

Reading's research outputs online 
1 The spatiotemporal variation and control mechanism of surface $p \mathrm{CO}_{2}$ in winter in Jiaozhou

3 Yunxiao Li ${ }^{\mathrm{a}}$, Hong Yang ${ }^{\mathrm{b}}$, Longjun Zhang ${ }^{\mathrm{c}}$, Xufeng Yang ${ }^{\mathrm{d}}$, Han Zang ${ }^{\mathrm{e}}$, Wenhua Fan ${ }^{\mathrm{a}}$, Gailing

$4 \quad$ Wang $^{\mathrm{a}}$

5 a Environment Science Laboratory, College of Resource and Environment, Shanxi Agricultural

6 University, Taigu 030801, China

7 b Department of Geography and Environmental Science, University of Reading, Whiteknights,

8 Reading RG6 6AB, UK

$9{ }^{\mathrm{c}}$ Key Laboratory of Marine Environmental Science and Ecology, Ministry of Education, College of

10 Environmental Science and Engineering, Ocean University of China, Qingdao 266100, China

11 d Second Institute of Oceanography, Ministry of Natural Resources, Hangzhou 310012, China

$12{ }^{\mathrm{e}}$ College of Environmental Science and Engineering, Shanghai Jiao Tong University, Shanghai

13200240 , China

$14{ }^{*}$ Corresponding author at: College of Environmental Science and Engineering, Ocean University of

15 China, Qingdao 266100, China.

16 E-mail address: longjunz@ouc.edu.cn (L Zhang). 


\section{Abstract}

In many mid-latitude coastal waters during winter months, in addition to temperature, the large change in biogeochemical processes often influence and complicate the surface partial pressure of $\mathrm{CO}_{2}\left(p \mathrm{CO}_{2}\right)$. Based on the hydrological and carbonate parameters in seven cruises, this study analysed the evolution process and explored the control mechanism of the surface $p \mathrm{CO}_{2}$ in Jiaozhou Bay, China, from December to March. The results showed that the $p \mathrm{CO}_{2}$ ranged from $157 \mu$ atm to $647 \mu \mathrm{atm}$, and the bay represented a sink for atmospheric $\mathrm{CO}_{2}\left(-3.8 \mathrm{mmol} \mathrm{m}^{-2} \mathrm{~d}^{-1}\right)$ in the whole winter. The non-temperature processes were the dominant factors affecting intra-winter $p \mathrm{CO}_{2}$ variation. In December, the bay was dominated by aerobic respiration and acted as a $\mathrm{CO}_{2}$ source $\left(3.0 \mathrm{mmol} \mathrm{m}^{-2} \mathrm{~d}^{-1}\right)$. From early January to late February, however, the vigorous growth of cold algae caused strong primary production, and the bay presented as a $\mathrm{CO}_{2} \operatorname{sink}$ (from $-6.4 \mathrm{mmol} \mathrm{m}^{-2} \mathrm{~d}^{-1}$ in early January to $-15.5 \mathrm{mmol} \mathrm{m}^{-2} \mathrm{~d}^{-1}$ in late February). In March, primary production weakened and the effects of the $\mathrm{CaCO}_{3}$ precipitation appeared, and the strength of the $\mathrm{CO}_{2}$ sink was obviously weakened $\left(-1.1 \mathrm{mmol} \mathrm{m}^{-2} \mathrm{~d}^{-1}\right)$. Meanwhile, the water temperature decreased gradually from December to late January and then increased until March, and it further expanded the variation range of $p \mathrm{CO}_{2}$. Our results highlight the obvious source/sink change in mid-latitude seawater $\mathrm{CO}_{2}$ in winter, while more field observations are still needed to further understand the complicated biogeochemical processes and its influence on seawater $p \mathrm{CO}_{2}$.

Keywords: $p \mathrm{CO}_{2}$; Aerobic respiration; Primary production; $\mathrm{CaCO}_{3}$ precipitation; Controlling mechanism; Jiaozhou Bay

\section{Introduction}

The absorption intensity of $\mathrm{CO}_{2}$ in coastal waters has received increasing attention (Borges, 2011; Cai et al., 2011; Gruber, 2015). The current estimate accounts for $10 \sim 20 \%$ of the $\mathrm{CO}_{2}$ absorbed by the world's oceans (Chen et al., 2013; Laruelle et al., 2014; Wanninkhof et al., 2013). However, the rapid change in biogeochemical processes produces large uncertainties in the estimates. Therefore, a more comprehensive and in-depth understanding of the spatiotemporal pattern and mechanisms controlling coastal $\mathrm{CO}_{2}$ system is extremely necessary. 
In winter, a decrease in seawater temperature increases the solubility of $\mathrm{CO}_{2}$, resulting in a decrease in the surface partial pressure of $\mathrm{CO}_{2}\left(p \mathrm{CO}_{2}\right)$. In most of the mid-latitude sea areas in the world, the temperature variation from summer to winter accounts for more than $50 \%$ of the change in $p \mathrm{CO}_{2}$ (Takahashi et al., 2002). Many studied areas, such as the western area of the North Atlantic Ocean (Heike et al., 2004), the North Sea (Thomas et al., 2005), the US South Atlantic Bight (Jiang et al., 2013) and the North Yellow Sea (Xue et al., 2012), have shown that low temperature in winter often results in low $p \mathrm{CO}_{2}$ levels, and some ocean areas even appear as sinks of atmospheric $\mathrm{CO}_{2}$. However, affected by the coupled influence of low temperature, vertical mixing, runoff variation, nutrient supply and light intensity in winter, vigorous growth of phytoplankton often occurs in many mid-latitude coastal waters, such as the waters near Blanca (Argentina) in South America (Popovich et al., 2008), the Narragansett Bay and the Sargasso Sea in North America (Oviatt et al., 2002; Tin et al., 2016), the waters near the Loire estuary and the Adriatic Sea in Europe (Guillaud et al., 2008; Ljubimir et al., 2017), and the nearshore areas of the Bohai Sea and the Hokkaido in North-east Asia (Sakamoto et al., 2008; Zhao et al., 2004). In addition, a certain degree of aerobic respiration occurs in some areas, for example, the central area of the Baltic Sea and the North Yellow Sea (Wesslander et al., 2010; Xu et al., 2016). Therefore, in addition to the effects of temperature variation, the influence of non-temperature biogeochemical processes on the $\mathrm{CO}_{2}$ source/sink change should not be neglected in mid-latitude coastal waters in winter.

The $\mathrm{CO}_{2}$ sinks caused by primary production in winter have been reported in some mid-latitude coastal waters. In the Patagonia Sea in South America, Bianchi et al. (2009) conducted a cruise survey in winter. Their results showed that $p \mathrm{CO}_{2}$ values had a significant negative correlation with Chlorophyll a $\left(\mathrm{Chl} a\right.$ ), and the region of $60 \sim 61.1^{\circ} \mathrm{W}$ with the highest $\mathrm{Chl} a$ value of $>3.5 \mu \mathrm{g} / \mathrm{L}$ acted as a sink of atmospheric $\mathrm{CO}_{2}$. In the nearshore areas of the Loire estuary, based on one cruise data in February, Bozec et al. (2012) found that the increase in river discharge promoted the vertical stratification of seawater and brought large amounts of nutrients. Consequently, the phytoplankton bloom consisting mainly of diatoms caused the seawater surface $p \mathrm{CO}_{2}$ to be lower than the atmosphere by $42 \mu \mathrm{atm}$. Regarding the phenomenon of an increase in $p \mathrm{CO}_{2}$ caused by aerobic respiration, Xu et al. (2016) found that vertical mixing carried the subsurface organic matter to the 
surface layer and aerobic respiration made the northern Yellow Sea act as a $\mathrm{CO}_{2}$ source in December (the average $p \mathrm{CO}_{2}$ was $464 \mu \mathrm{atm}$ ). In spite of some field observation in different areas, more cruise surveys and analyses are still needed to more comprehensively reveal the detailed spatiotemporal pattern of $p \mathrm{CO}_{2}$ and its control mechanisms throughout the winter months.

Jiaozhou Bay (JZB) $\left(35^{\circ} 18^{\prime} \sim 36^{\circ} 18^{\prime} \mathrm{N}, 120^{\circ} 04^{\prime} \sim 120^{\circ} 23^{\prime} \mathrm{E}\right)$ is a typical mid-latitude semiclosed shallow water in northern China. The water area is $302.9 \mathrm{~km}^{2}$ and the average water depth is $7 \mathrm{~m}$. The climate is dominated by the East Asia Monsoon, with northerly wind in winter and southerly wind in summer (Li et al., 2006). The tidal current is a regular semi-diurnal tide that induces strong vertical mixing and good vertical homogeneity of the seawater temperature and salinity (Chen et al.,1999; Liu et al., 2004). The bay is an ideal area for characterizing the natural variation in $p \mathrm{CO}_{2}$ and understanding their controlling processes, particularly in winter. First, as a typical mid-latitude water body, JZB has a strong seasonal change of physically properties. In particular, the average seawater surface temperature increases by $\sim 10{ }^{\circ} \mathrm{C}$ from winter to spring ( $\mathrm{Li}$ et al., 2007). Second, approximately $37 \%$ of the human population in the world lives within $100 \mathrm{~km}$ of the coastline (Cohen et al., 1997) and especially in the mid-latitude area, making this area subject to intense human impact (Bauer et al., 2013). JZB is a typical bay that is highly affected by urbanization. The eastern area of the bay is adjacent to the downtown of Qingdao City, with a population of 4.8 million, and the major estuaries (Licun River, Haibo River and Loushan River) have already become conduits for wastewater (Gao et al., 2008). Large amounts of nutrient and organic pollutant input have caused eutrophication and other problems in the JZB, with strong influence on carbon cycle in the area (Wang and Wang, 2011). The measurement of phytoplankton biomass, determined by using $\mathrm{Chl} a$, in the past two decades indicated a clear bimodal pattern with peaks in summer and winter in the bay (Sun et al.,2011a; Wang et al., 2015; Wu et al., 2004). Same as many coasts in China, JZB is also an important shellfish-farming area with a breeding area of $107 \mathrm{~km}^{2}$ (Yang et al., 2007; Zhang et al., 2005), suggesting the possible effect of calcification on $p \mathrm{CO}_{2}$.

In the previous studies on controlling mechanisms of $p \mathrm{CO}_{2}$ in the JZB during winter, Zhang et al. (2012) conducted one cruise in autumn and the other in winter. Their results indicated that the 
100 bay experienced a process of intense organic degradation in autumn and strong primary production

101 in winter, causing the bay from a $\mathrm{CO}_{2}$ source to a sink during the period. Recently, Zang et al. (2018)

102 found that the decrease in seawater temperature and enhancement of primary production together

103 resulted in the bay acting as a $\mathrm{CO}_{2}$ sink. However, $p \mathrm{CO}_{2}$ changes throughout the winter and the

104 mechanism for the variation are far from clearly understood. To fill the knowledge gap, this study

105 researched the variation in seawater surface $p \mathrm{CO}_{2}$ from December to March in the JZB and explored

106 the factors determining the change of $p \mathrm{CO}_{2}$. In particular, this study analysed the effect of the

107 biogeochemical process induced by phytoplankton bloom on $\mathrm{CO}_{2}$ source/sink patterns, with the

108 consideration of water temperature variation (decrease first and increase later). The results can

109 improve the understanding of the $p \mathrm{CO}_{2}$ control mechanism in mid-latitude coastal waters where

110 strong biological activities occur in winter.

\section{2. Material and methods}

\section{$112 \quad 2.1$ Survey stations and sample processing}

113 Seven cruises were conducted in the JZB during winter from 2008 to 2016. Survey time and

114 number of stations are listed in Table 1. In each cruise, samples were collected from 24 33 stations

115 (Figure 1). During the cruises, seawater samples were collected from the water surface at a depth of

116 approximately $1.5 \mathrm{~m}$ because of the homogeneous vertical profiles in the JZB water column (Chen

117 et al., 1999). Seawater surface temperature, salinity, oxygen saturation (DO\%) and $p \mathrm{CO}_{2}$ data were

118 collected continuously, and discrete water samples were collected using 5 L Niskin bottles for later

119 analysis of dissolved inorganic carbon (DIC), total alkalinity (TA), and Chl $a$.

120 Surface temperature and salinity were measured using a SBE 45 Micro TSG (Sea-Bird, Inc.,

121 Bellevue, WA, USA), with a nominal precision of $0.002{ }^{\circ} \mathrm{C}$ for temperature and 0.005 for salinity.

122 The DO\% was measured with a YSI-5000 oxygen analyser (YSI Corporation, Yellow Spring, OH,

123 USA), which was calibrated using the Winkler titration method (nominal precision: $0.1 \%$ ). The

124 surface $p \mathrm{CO}_{2}$ was measured with a non-dispersive infrared (NDIR) spectrometer (Li-Cor Model Li-

125 7000, Lincoln, NE, USA) or a G2131-I Analyser (PICAROO, USA) using wavelength-scanned

126 cavity ring-down spectroscopy (WS-CRDS), coupled to an equilibrator. The $p \mathrm{CO}_{2}$ data in cruises

127 before 2014 were measured using a Li-7000 NDIR spectrometer with a measurement uncertainty of 
128 less than 1\%, and those in 2014 and after were measured using a G2131-I Analyser with a nominal

129 precision of $<50 \mathrm{ppbv}$ over 5-min intervals. Before and after each cruise, the $p \mathrm{CO}_{2}$ measurement

130 instruments were calibrated against three $\mathrm{CO}_{2}$ gas standards (202, 401 and $1010 \mathrm{ppm} \mathrm{CO}_{2}$ in air)

131 and one $\mathrm{N}_{2}$ reference (National Research Center for Certified Reference Materials, Beijing, China).

132 To measure DIC and TA of water samples, filtration treatment was needed to avoid the

133 influence of the particular matter. The DIC samples were directly collected from the Niskin bottles

134 using a syringe and filtered through a $0.45 \mu \mathrm{m}$ disposable syringe filter to avoid exchange with the

135 air. TA samples were filtered through cellulose acetate membranes $(0.45 \mu \mathrm{m})$ using a borosilicate

136 glass filter. The DIC and TA samples were all poisoned with saturated mercury chloride (final

137 concentration: c. $0.02 \%$ by volume) and preserved at $4{ }^{\circ} \mathrm{C}$ ( $\mathrm{Li}$ et al., 2017). The DIC values were

138 determined by acid extraction using a total organic analyser (TOC-VCPN, Shimadzu Corporation,

139 Kyoto, Japan) (Liu et al., 2014) or a DIC analyser (AS-C2, Apollo SciTech, USA). The TA values

140 were determined by Gran titration using a Total Alkalinity Titrator (AS-ALK2, Apollo SciTech,

141 USA). Measurements of DIC and TA were both calibrated against Certified Reference Materials

142 (CRMs) from Scripps Institution of Oceanography at a precision and accuracy level of $0.2 \%$.

143 Samples for Chl $a$ measurement were filtered through GF/F glass fibre membranes $(0.7 \mu \mathrm{m}$;

144 Whatman, Maidstone, UK) at pressures below 0.04 MPa. Saturated magnesium carbonate was

145 added to the membranes after filtration, and the samples were preserved at $-20^{\circ} \mathrm{C}$. Before analysis,

146 the samples were extracted with $90 \%$ acetone, and the supernatant fluid was analysed using a

147 fluorescence spectrophotometer (F4500, Hitachi Co, Tokyo, Japan).

$148 \quad$ 2.2. Methodology

\section{$149 \quad$ 2.2.1. Aragonite saturation state}

150 The aragonite saturation state $\left(\Omega_{\mathrm{arag}}\right)$ at in situ temperatures $\left(\Omega_{\mathrm{arag}} @\right.$ situ $)$ was calculated from

151 the DIC, TA, in situ temperature, and in situ salinity values using the $\mathrm{CO}_{2}$ program (Lewis and

152 Wallace, 1998) and the $\mathrm{CO}_{2}$ system coefficients of Mehrbach et al. (1973) as refitted by Dickson

153 and Millero (1987). The Ksp* values for aragonite were taken from Mucci (1983), and the $\mathrm{Ca}^{2+}$

154 concentrations were assumed to be proportional to salinity, as presented in Millero (1979). 


\subsection{2. $p \mathrm{CO}_{2}$ normalization}

Considering that our $p \mathrm{CO}_{2}$ data were collected over several years, this study normalized the surface water $p \mathrm{CO}_{2}$ values of the cruises in December to the year 2015 and those of other cruises to the year 2016 by assuming that seawater surface $p \mathrm{CO}_{2}$ increased at the same growth rate $(1.5 \mu \mathrm{atm}$ $\left.\mathrm{yr}^{-1}\right)$ of the $p \mathrm{CO}_{2}$ in the air according to Nakaoka et al. (2006).

\subsubsection{The temperature effect on $p \mathrm{CO}_{2}$}

To assess the temperature effect on the distribution of $p \mathrm{CO}_{2}$ in each cruise, this study normalized the observed in situ $p \mathrm{CO}_{2}$ data to the average seawater temperature of the corresponding cruise using the equations proposed by Takahashi et al. (1993), and then temperature-normalized $p \mathrm{CO}_{2}$ $\left(\mathrm{n} p \mathrm{CO}_{2}\right)$ was calculated:

$$
\mathrm{n} p \mathrm{CO}_{2}=\left(p \mathrm{CO}_{2}\right)_{\text {obs }} \times \operatorname{EXP}\left[0.0423 \times\left(\mathrm{T}_{\text {nor }}-\mathrm{T}_{\mathrm{obs}}\right)\right]
$$

where $\left(p \mathrm{CO}_{2}\right)_{\text {obs}}, \mathrm{T}_{\mathrm{obs}}$ and $\mathrm{T}_{\text {nor }}$ are the observed in situ surface $p \mathrm{CO}_{2}$, in situ temperature and the temperature to which the in situ $p \mathrm{CO}_{2}$ needs to be normalized, respectively. Then, the difference between $\mathrm{n} p \mathrm{CO}_{2}$ and $\left(p \mathrm{CO}_{2}\right)_{\text {obs }}$ was the temperature effect on $p \mathrm{CO}_{2}$ distribution in the cruise.

Similarly, to assess the temperature effect on $p \mathrm{CO}_{2}$ between the cruises, the average $p \mathrm{CO}_{2}$ for each cruise was normalized to the average seawater temperature of all cruises. Then, the $p \mathrm{CO}_{2}$ in each cruise under the average seawater temperature in winter $\left(\mathrm{N} p C O_{2}\right)$ was calculated:

$$
\mathrm{N} p \mathrm{CO}_{2}=\left(p \mathrm{CO}_{2}\right)_{\text {mean }} \times \mathrm{EXP}\left[0.0423 \times\left(\mathrm{T}_{\text {Mean }}-\mathrm{T}_{\text {mean }}\right)\right]
$$

where $\left(p \mathrm{CO}_{2}\right)_{\text {mean }}$ and $\mathrm{T}_{\text {mean }}$ are the average surface $p \mathrm{CO}_{2}$ and temperature in each cruise. $\mathrm{T}_{\text {Mean }}$ is the average seawater temperature of all cruises.

To assess the relative importance of temperature and non-temperature effect (including the effect of biological activities) on $p \mathrm{CO}_{2}$ between the cruises, this study used equations developed by Takahashi et al. (2002):

$$
\begin{aligned}
& \mathrm{T}: p \mathrm{CO}_{2} \text { at } \mathrm{T}_{\mathrm{obs}}=\left(p \mathrm{CO}_{2}\right)_{\text {Mean }} \times \operatorname{EXP}\left[0.0423 \times\left(\mathrm{T}_{\mathrm{obs}}-\mathrm{T}_{\text {Mean }}\right)\right] \\
& \text { B: } p \mathrm{CO}_{2} \text { at } \mathrm{T}_{\text {Mean }}=\left(p \mathrm{CO}_{2}\right)_{\text {obs }} \times \operatorname{EXP}\left[0.0423 \times\left(\mathrm{T}_{\text {Mean }}-\mathrm{T}_{\text {obs }}\right)\right] \\
& \Delta\left(p \mathrm{CO}_{2}\right)_{\text {non-temp }}=\left(p \mathrm{CO}_{2} \text { at } \mathrm{T}_{\text {Mean }}\right)_{\max }-\left(p \mathrm{CO}_{2} \text { at } \mathrm{T}_{\text {Mean }}\right)_{\text {min }} \\
& \Delta\left(p \mathrm{CO}_{2}\right)_{\text {temp }}=\left(p \mathrm{CO}_{2} \text { at } \mathrm{T}_{\text {obs }}\right)_{\text {max }}-\left(p \mathrm{CO}_{2} \text { at } \mathrm{T}_{\mathrm{obs}}\right)_{\text {min }}
\end{aligned}
$$


182 where $\left(p \mathrm{CO}_{2}\right)_{\text {Mean }}$ is the average $p \mathrm{CO}_{2}$ of all cruises, and the subscripts "max" and "min" indicated

183 the maximum and minimum values, respectively.

184 The relative importance of each effect can be expressed in terms of the ratio between the

185

186

187

188

189

190

191

192

193

194

195

196

197

198

199

200

201

202

203

204

205

206

207

208 temperature effect $(\mathrm{T})$ and non-temperature effect $(\mathrm{B})$ :

$$
\mathrm{T} / \mathrm{B}=\Delta\left(p \mathrm{CO}_{2}\right)_{\text {temp }} / \Delta\left(p \mathrm{CO}_{2}\right)_{\text {non-temp }}
$$

\subsubsection{Statistical analyses}

The correlations between environmental variables were analysed using SPSS 21 (IBM SPSS Statistics, IBM Corporation, Armonk, New York). All statistical analyses were at significance level of 0.05 .

\section{Results}

\subsection{Temperature and salinity}

The seawater temperature in the JZB in winter is shown in Figure 2. The temperatures in the seven cruises surveyed were all below $10{ }^{\circ} \mathrm{C}$, and the average temperature decreased from $7.1{ }^{\circ} \mathrm{C}$ in December to $1.5^{\circ} \mathrm{C}$ in late January and then gradually increased to $8.6^{\circ} \mathrm{C}$ in March. The time span of seven cruises ( 8 years) was relatively large. Compared with the multi-year diurnal average seawater temperature data in the JZB during winter, the temperature in the five cruises from December to late January was slightly lower and that in March. Even so, the overall variation trends of temperature in these cruises were consistent with the changes of daily seawater temperature, showing that these cruise data had a certain representativeness and can be used to analyse the $p \mathrm{CO}_{2}$ variation between winter months in the JZB. The temperature increased from the upper end of the bay to the mouth of the bay in the five cruises from December to late January (Figure 3). The temperature gradient in each cruise in this period was relatively large, and the difference between the lowest and the highest temperature values all exceeded $4.0^{\circ} \mathrm{C}$. The temperature values in the two cruises during December were the highest $\left(4.4 \sim 9.0^{\circ} \mathrm{C}\right.$ and $\left.3.9 \sim 9.7^{\circ} \mathrm{C}\right)$, while the temperature values in the cruise in late January were the lowest $\left(-1.3 \sim 4.6^{\circ} \mathrm{C}\right)$. In late February, due to the impact of land warming, no obvious temperature difference between the upper end of the bay and the mouth area existed. The temperature in this period was evenly distributed with a range of $3.8 \sim 4.7^{\circ} \mathrm{C}$. In 
209 March, the temperature decreased from the upper end of the bay to the mouth, with a range of $210 \quad 7.7 \sim 9.9^{\circ} \mathrm{C}$.

211 The seawater surface salinity values in December and early January were relatively close and 212 were basically between 29.0 and 30.9 (Figure 2). In the four cruises from mid-January to March, 213 the salinity levels were higher with values of $>30.3$. In late January, the salinity values were the 214 highest throughout the winter and ranged from 30.9 to 31.7. In late February and March, the salinity 215 decreased slightly, and the ranges were $30.3 \sim 31.2$ and 30.5 31.2, respectively. In terms of 216 distribution in these seven cruises (Figure 3), the salinity increased from the northeastern area to the 217 mouth, and the difference between the highest and lowest values in each cruise was less than 2.0. 218 The salinity in the northeastern area was always the lowest, and the gradient variation was relatively 219 large, indicating the influence of terrestrial input. The rivers entering the JZB have no natural runoff 220 and the winter is the dry season. However, three wastewater treatment plants located near the 221 northeastern area and the daily total amount of treated sewage is up to $\sim 510000$ tons, indicating that 222 the direct treated sewage input was the main reason for the low salinity in this region.

\section{$223 \quad 3.2 \mathrm{pCO}_{2}$}

The distribution of seawater surface $p \mathrm{CO}_{2}$ in the $\mathrm{JZB}$ in winter is shown in Figure 4. According to the average air $\mathrm{CO}_{2}$ data $(408 \mu \mathrm{atm})$ from December 2015 to March 2016 from the flask measurements on the Tae-ahn Peninsula $\left(126.131^{\circ} \mathrm{E}, 36.731^{\circ} \mathrm{N}\right)$ adjacent to the southern Yellow Sea,

227 the bay in two cruises during December acted as a source of atmospheric $\mathrm{CO}_{2}$ as a whole, and the $228 \quad p \mathrm{CO}_{2}$ ranges were 379 536 $\mu \mathrm{atm}$ and 382 647 $\mu \mathrm{atm}$, respectively. The $p \mathrm{CO}_{2}$ gradually decreased 229 from the northeastern area to the mouth area. Obviously, the $p \mathrm{CO}_{2}$ in the northeastern area was the

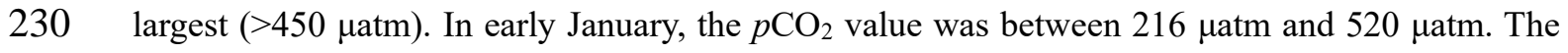
231 northeastern area also acted as a $\mathrm{CO}_{2}$ source, but the western area was unsaturated with respect to 232 atmospheric $\mathrm{CO}_{2}$. In mid-January (282 375 $\left.\mu \mathrm{atm}\right)$, late January (202 324 $\left.\mu \mathrm{atm}\right)$ and late February 233 (157 327 $\mu \mathrm{atm})$, the $\mathrm{CO}_{2}$ levels in the entire bay were all unsaturated and the $p \mathrm{CO}_{2}$ decreased from 234 the mouth to the northeastern area. The $\mathrm{PCO}_{2}$ value in the northeastern area was even below 190 $235 \mu$ atm in late February. In March, the bay acted as a weak $\mathrm{CO}_{2}$ sink as a whole with the $p \mathrm{CO}_{2}$ values of $357 \sim 415 \mu \mathrm{atm}$. The $p \mathrm{CO}_{2}$ value was highest in the northern area and decreased gradually to the 
mouth area, while the difference of $p \mathrm{CO}_{2}$ between areas did not exceed $50 \mu \mathrm{atm}$. Overall, the $p \mathrm{CO}_{2}$

238 values throughout the winter showed a process of gradual decrease from December to the end of

239 February and then obvious increase in March (Figure 4h). The average $p \mathrm{CO}_{2}$ value of all cruises 240 was $352 \mu \mathrm{atm}$. Therefore, the bay acted as a sink of atmospheric $\mathrm{CO}_{2}$ in winter as a whole.

\section{$241 \quad 3.3 \mathrm{DO} \%$ and Chl $a$}

242 The distribution of seawater surface DO\% in the JZB in winter is shown in Figure 5. The 243 seawater surface DO in the JZB was unsaturated in both cruises in December (ranges: 79.8 98.1\% 244 and 79.5 101.5\%) and increased from the northeastern area to the mouth area. In the northeastern 245 area, which acted as the strongest $\mathrm{CO}_{2}$ source, the unsaturated degree of DO was the highest and 246 the DO\% values were approximately $85 \%$, showing the presence of aerobic respiration. In early 247 January, DO remained unsaturated in the northeastern area which acted as a $\mathrm{CO}_{2}$ source, but 248 oversaturated $(\sim 105 \%)$ in the western area which acted as a $\mathrm{CO}_{2}$ sink. In mid-January, late January 249 and late February, when the entire JZB acted as a $\mathrm{CO}_{2}$ sink, the $\mathrm{DO} \%$ ranges were $101.0 \sim 117.5 \%$, $250109.4 \sim 120.2 \%$ and $102.0 \sim 147.0 \%$, respectively. In these three cruises, DO was oversaturated and 251 decreased from the northeastern area to the mouth area. Moreover, in the northeastern area, DO\% 252 values were highest and were above $110 \%$ (mid-January), $115 \%$ (late January) and $125 \%$ (late 253 February), respectively, showing a strong primary production process. In March, the DO was 254 slightly oversaturated with DO\% values of $103.2 \sim 114.8 \%$. The DO\% distribution in the bay was 255 relatively uniform, and the values in most areas were approximately $109.0 \%$. Overall, the variation 256 trend of $\mathrm{DO} \%$ throughout the winter was opposite to $p \mathrm{CO}_{2}$, a process of gradual increase from 257 December to late February and then decrease in March (Figure 5h).

258 The distribution of seawater surface Chl $a$ in the JZB in winter is shown in Figure 5. The Chl $259 a$ concentration was low and below $0.60 \mu \mathrm{g} / \mathrm{L}$ in December when the DO was unsaturated. The 260 ranges of $\mathrm{Chl} a$ in these two cruises were $0.03 \sim 0.61 \mu \mathrm{g} / \mathrm{L}$ and $0.12 \sim 0.55 \mu \mathrm{g} / \mathrm{L}$, respectively. In early 261 January, the Chl $a$ concentrations in the western and mouth areas were above $0.60 \mu \mathrm{g} / \mathrm{L}$. In mid262 January, late January and late February, when the DO in the entire bay was oversaturated, the ranges 263 of Chl $a$ were $0.30 \sim 2.30 \mu \mathrm{g} / \mathrm{L}, 0.40 \sim 9.12 \mu \mathrm{g} / \mathrm{L}$ and $1.78 \sim 8.94 \mu \mathrm{g} / \mathrm{L}$, respectively. The $\mathrm{Chl} a$ 264 concentrations in the three cruises all decreased from the northeastern area to the mouth, and the 
$265 \mathrm{Chl} a$ concentrations in the northeastern area were above $1.50 \mu \mathrm{g} / \mathrm{L}, 4.50 \mu \mathrm{g} / \mathrm{L}$ and $6.50 \mu \mathrm{g} / \mathrm{L}$, 266 respectively. In March, when the DO was slightly oversaturated, the Chl $a$ concentration was lower 267 with Chl $a$ values of $0.04 \sim 0.40 \mu \mathrm{g} / \mathrm{L}$. Overall, the variation of phytoplankton biomass represented 268 by Chl $a$ concentration throughout the winter was in good agreement with that of DO\%, showing a 269 process of gradual increase from December to the end of February and then obvious decrease in 270 March (Figure 5h).

\section{$271 \quad 3.4$ DIC and TA}

272 The seawater surface DIC in the JZB in winter is shown in Figure 6. In December and early 273 January, the DIC levels were relatively high and generally ranged between $2100 \mu \mathrm{mol} / \mathrm{kg}$ and 2300 $274 \mu \mathrm{mol} / \mathrm{kg}$. The DIC values were highest in the northeastern area and decreased gradually to the mouth, 275 with the difference of approximately $150 \mu \mathrm{mol} / \mathrm{kg}$. In these two periods, the difference in DIC 276 distribution mainly occurred in the western area of the bay. In December, the DIC in the western 277 area was approximately $40 \mu \mathrm{mol} / \mathrm{kg}$ higher than that in the mouth, but they were close in early 278 January. In middle and late January, the DIC values $(2142 \sim 2156 \mu \mathrm{mol} / \mathrm{kg}$ and $2130 \sim 2155 \mu \mathrm{mol} / \mathrm{kg})$ 279 were lower than those in December. The DIC also decreased from the northeastern area to the mouth 280 area, but the difference between two areas was much smaller, just $\sim 15 \mu \mathrm{mol} / \mathrm{kg}$. In late February, 281 the DIC values were the lowest throughout the winter, with a range of $2000 \sim 2140 \mu \mathrm{mol} / \mathrm{kg}$. The

282 DIC value increased gradually from the northeastern area to the mouth area and the difference was 283 up to $\sim 90 \mu \mathrm{mol} / \mathrm{kg}$. In March, the DIC values (2085 2126 $\mu \mathrm{mol} / \mathrm{kg})$ also maintained a lower level 284 but increased from the north area to the mouth area, with the difference of $\sim 20 \mu \mathrm{mol} / \mathrm{kg}$ between 285 two areas.

286 Seawater surface TA in the JZB during winter is shown in Figure 6. In December and early 287 January, the TA values ranged generally between $2240 \mu \mathrm{mol} / \mathrm{kg}$ and $2400 \mu \mathrm{mol} / \mathrm{kg}$. The spatial 288 distribution of TA was similar to that of DIC. The TA values were also highest in the northeastern 289 area and decreased gradually to the mouth. However, the decreasing gradient of TA was slightly 290 smaller than that of DIC, and the TA difference between the northeastern and the mouth area was 291 approximately $110 \mu \mathrm{mol} / \mathrm{kg}$. In early January, TA values in the western area (where DIC values were close to those in the mouth area) were $\sim 30 \mu \mathrm{mol} / \mathrm{kg}$ higher than those in the mouth area. In middle 
and late January, the TA ranges were 2297 2336 $\mu \mathrm{mol} / \mathrm{kg}$ and $2302 \sim 2360 \mu \mathrm{mol} / \mathrm{kg}$, respectively.

294 Compared to December, the TA values of these two cruises were slightly higher in most areas except for the northeastern area, and the TA difference between the northeastern area and the mouth area was only $\sim 45 \mu \mathrm{mol} / \mathrm{kg}$. In late February, the TA was between $2302 \mu \mathrm{mol} / \mathrm{kg}$ and $2364 \mu \mathrm{mol} / \mathrm{kg}$, and the spatial distribution was opposite to that of DIC. The TA value was highest in the northeastern area with low DIC and increased gradually to the mouth area. In March, the TA value ranged from $2290 \mu \mathrm{mol} / \mathrm{kg}$ to $2347 \mu \mathrm{mol} / \mathrm{kg}$. Spatial distribution of TA was similar to that of DIC, and the TA

300 values increased from the northern area to the mouth area. However, the change gradient of TA was 301 larger than that of DIC, and the TA values in the northern area were $\sim 40 \mu \mathrm{mol} / \mathrm{kg}$ lower than those 302 in the mouth.

\section{4. Discussion}

\section{$304 \quad 4.1$ The temperature effect on variation in surface $p \mathrm{CO}_{2}$ in the $\mathrm{JZB}$ during winter}

Temperature is an important thermodynamic parameter affecting seawater $p \mathrm{CO}_{2}$. For example, the relationship between seawater temperature and $p \mathrm{CO}_{2}$ proposed by Takahashi et al. (1993) shows

307 that $p \mathrm{CO}_{2}$ decreases by approximately $4.23 \%$ for every $1{ }^{\circ} \mathrm{C}$ decrease in water temperature. To 308 assess the temperature effect on the $p \mathrm{CO}_{2}$ distribution for each cruise, this study calculated $\mathrm{n} p \mathrm{CO}_{2}$ 309 by normalizing the surface $p \mathrm{CO}_{2}$ at each station to the average seawater temperature in the corresponding cruise (see Section 2.3.3 Methodology). As shown in Figure 7a-g, in December $\left(13^{\text {th }}\right.$ 311 and $\left.21^{\text {st }}\right)$, early January $\left(8^{\text {th }}\right)$, mid-January $\left(21^{\text {st }}\right)$, and late January $\left(26^{\text {th }}\right)$, the $p \mathrm{CO}_{2}$ in the upper end 312 of the bay with lower temperatures increased by $20 \sim 65 \mu$ atm after normalization, while the $p \mathrm{CO}_{2}$ in 313 the mouth area of the bay with higher temperatures decreased by $15 \sim 30 \mu \mathrm{atm}$. This indicated that 314 surface $p \mathrm{CO}_{2}$ in the nearshore area was relatively low due to the cooling effect of land, whereas that 315 in the mouth area was higher due to the frequent water exchange with the Yellow Sea where water 316 temperature was relatively higher. In March $\left(25^{\text {th }}\right)$, the $p \mathrm{CO}_{2}$ in the upper end of the bay with higher 317 temperature decreased by $\sim 12 \mu$ atm after normalization, while the $p \mathrm{CO}_{2}$ in the mouth area with 318 lower temperature increased by $\sim 12 \mu \mathrm{atm}$, suggesting that land warming resulted in higher $p \mathrm{CO}_{2}$ in 319 the upper end area. All these results indicated the temperature effect on the spatial distribution of $p \mathrm{CO}_{2}$ in certain periods of winter. However, combined with the distribution of in situ $p \mathrm{CO}_{2}$ in each 
cruise (Figure 4), in mid-January and late January, the in situ $p \mathrm{CO}_{2}$ value in the northeastern area was lower than that in the mouth area by about $\sim 80 \mu \mathrm{atm}$, which was larger than the contribution of $p \mathrm{CO}_{2}(\sim 50 \mu \mathrm{atm})$ caused by the difference in water temperature. In March, the in situ $p \mathrm{CO}_{2}$ value in the northeastern was higher than that in the mouth area by about $50 \mu \mathrm{atm}$, which was also larger than the contribution of $p \mathrm{CO}_{2}(\sim 24 \mu \mathrm{atm})$ caused by the difference in water temperature. This indicated that the spatial distribution of $p \mathrm{CO}_{2}$ was still largely affected by other factors. Even in some cruises, temperature may not be the main factor controlling $p \mathrm{CO}_{2}$ distribution. For example,

328 in December, in situ $p \mathrm{CO}_{2}$ was the lowest in the mouth area with higher temperatures and the highest 329 in the northeastern waters with lower temperatures. In late February, the difference between the 330 highest and lowest seawater temperature was only $0.9^{\circ} \mathrm{C}$, but the difference in in situ $p \mathrm{CO}_{2}$ was 331 more than $160 \mu \mathrm{atm}$ (Figures 4, 7).

The seawater surface temperature in the JZB experienced a pattern of first decrease and then increase from December to March. To assess the temperature effect on the $p \mathrm{CO}_{2}$ variation between cruises, the $\mathrm{N} p \mathrm{CO}_{2}$ was calculated by normalizing the average seawater $p \mathrm{CO}_{2}$ in each cruise to the 335 average seawater temperature of all cruises $\left(5.2^{\circ} \mathrm{C}\right.$ ) (see Section 2.3.3 Methodology) (Figure 8). 336 After normalization, the $p \mathrm{CO}_{2}$ decreased by $33 \mu \mathrm{atm}$ and $51 \mu \mathrm{atm}$ in December and March, 337 respectively, when the temperatures were relative higher; the $p \mathrm{CO}_{2}$ increased by $20 \mu \mathrm{atm}, 21 \mu \mathrm{atm}$, $33847 \mu \mathrm{atm}$, and $12 \mu \mathrm{atm}$ in early January, mid-January, late January and late February, respectively, 339 when the temperatures were relative lower. The difference of $p \mathrm{CO}_{2}$ between cruises decreased by $34074 \%$ from December to early January and 52\% from late February to March, but it only decreased 341 by $8 \%$ from early January to late February. Moreover, the overall the temporal pattern of $p \mathrm{CO}_{2} \mathrm{kept}$ 342 stable. The highest and lowest $p \mathrm{CO}_{2}$ values still appeared in December and late February, 343 respectively, and the difference between months was up to $130 \mu \mathrm{atm}$. It indicated that the 344 temperature effect may play an important but not a dominant role in the whole intra-winter $p \mathrm{CO}_{2}$ 345 variation. Based on the method proposed by Takahashi et al. (2002) (see Section 2.3.3 Methodology), 346 the relative contributions of temperature $(\mathrm{T})$ and non-temperature effect $(\mathrm{B})$ to $p \mathrm{CO}_{2}$ variation 347 throughout the winter were calculated. It is noteworthy that this method was originally designed for 348 open oceanic systems and the non-temperature effect could be attributed almost entirely to the "net 
biology effect". However, it had been widely used by other authors to assess the role of temperature

350 versus biological factors in the control of $\mathrm{pCO}_{2}$ dynamics in coastal areas (de la Paz et al., 2009;

351 Ribas et al., 2011). The non-temperature term for coastal waters includes all the biogeochemical

352 processes acting on $\mathrm{CO}_{2}$. In this study, the $\mathrm{T} / \mathrm{B}$ ratio was 0.81 , indicating the main role of the non-

353 temperature effect in intra-winter $p \mathrm{CO}_{2}$ variation.

\section{4.2 The non-conservative behaviour of DIC and TA and variation in the JZB during winter}

In coastal waters, the non-temperature processes influencing $p \mathrm{CO}_{2}$ mainly includes terrestrial input, biological processes (production/respiration), $\mathrm{CaCO}_{3}$ processes (precipitation/dissolution), $\mathrm{CO}_{2}$ sea-air exchange (evasion/invasion) and others. The occurrence of these processes often changes DIC and TA. Therefore, the analysis of DIC and TA non-conservative behaviour is helpful

359 for identifying the main non-temperature factors for $p \mathrm{CO}_{2}$ (Jiang et al., 2013; Li et al., 2017; Zhai 360 et al., 2015). In some nearshore bays with no obvious runoff input, the ocean end-member can be used as a standard value to evaluate the effects of terrestrial input and biogeochemical processes, that is, the deviation of the measured DIC or TA from the ocean end-member. Thus, according to

363 the approach of Jiang et al. (2013), the values for the addition or removal of DIC and TA in each 364 cruise were obtained using the station data in the mouth area, which could represent the DIC and 365 TA levels of the Yellow Sea, as the seawater end-member values (Li et al., 2017, Yang et al., 2018). 366 In the specific calculation in late January, considering that the DO $\%$ in the mouth area was 367 approximately $110 \%$ and a certain primary production existed (Figure 5e), this study chose the ocean 368 end-member in mid-January, which was only 5 days apart. The calculation method is as follows:

$$
\begin{gathered}
\Delta \mathrm{DIC}=\mathrm{DIC}_{\mathrm{i}}-\frac{\mathrm{S}_{\mathrm{i}}}{\mathrm{S}_{\text {ocean }}} \times \mathrm{DIC}_{\text {ocean }} \\
\Delta \mathrm{TA}=\mathrm{TA}_{\mathrm{i}}-\frac{\mathrm{S}_{\mathrm{i}}}{\mathrm{S}_{\text {ocean }}} \times \mathrm{TA}_{\text {ocean }}
\end{gathered}
$$

371 where $\Delta \mathrm{DIC}$ and $\Delta \mathrm{TA}$ represent the addition and removal of DIC and TA, respectively; and $\mathrm{S}_{\mathrm{i}}\left(\mathrm{S}_{\text {ocean }}\right)$,

$372 \mathrm{DIC}_{\mathrm{i}}\left(\mathrm{DIC}_{\text {ocean }}\right)$, and $\mathrm{TA}_{\mathrm{i}}\left(\mathrm{TA}_{\text {ocean }}\right)$ are the salinity, DIC and $\mathrm{TA}$ of station $\mathrm{i}$ (the ocean end-member), 373 respectively. This study used the average values of DIC and TA from the two stations, which had 374 the highest salinity and were near the Yellow Sea, as the ocean end-member. The specific values are 375 shown in Table 2. 
As shown in Figure 9, the non-conservative behaviours of DIC and TA in the JZB presented three stages. First, $\triangle \mathrm{DIC}$ and $\Delta \mathrm{TA}$ maintained an addition status in the two cruises in December. The maximum addition values were observed in the northeastern area with low salinity and exceeded $200 \mu \mathrm{mol} / \mathrm{kg}$, showing the effect of terrestrial DIC and TA input. The altered ratio of $\Delta \mathrm{DIC}$ and $\triangle \mathrm{TA}$ from terrestrial input was generally close to 1:1 (Cai et al., 2008), but the $\triangle \mathrm{DIC}$ in the JZB was obviously larger than $\Delta \mathrm{TA}$ in this period. Moreover, the difference between $\Delta \mathrm{DIC}$ and $\Delta \mathrm{TA}$ was the largest in the northeastern area (more than $90 \mu \mathrm{mol} / \mathrm{kg}$ ), indicating that in addition to terrestrial input, other factors influenced DIC. Second, in the four cruises from early January to late February, $\Delta \mathrm{TA}$ values also presented an addition status. However, there was a phenomenon that $\Delta \mathrm{DIC}$ was less than $\Delta \mathrm{TA}$. In early January, this situation only occurred in the western area. In mid-January,

386 this situation expanded to the entire bay. In late January and late February, the DIC showed partial 387 or complete removal in different stations. The results indicated that DIC experienced an obvious consumption in this period. Finally, in March, both DIC and TA showed a removal status, and the removal of TA was greater than that of DIC. The maximum removals of TA and DIC were close to

$39030 \mu \mathrm{mol} / \mathrm{kg}$ and $20 \mu \mathrm{mol} / \mathrm{kg}$, respectively. This suggested that the processes consuming DIC and TA 391 existed in the meantime. Thus, the influences of non-temperature processes on $p \mathrm{CO}_{2}$ were discussed in each period separately.

4.3 Aerobic respiration caused the bay to act as a $\mathrm{CO}_{2}$ source in early winter

The biogeochemical processes that cause the non-conservative behaviour of DIC and TA could alter $\triangle \mathrm{DIC}$ and $\Delta \mathrm{TA}$ in fixed ratios. By comparing the ratio of $\Delta \mathrm{TA}$ to $\Delta \mathrm{DIC}$ at each station with the fixed ratios of the various processes that alter $\Delta \mathrm{TA}$ and $\Delta \mathrm{DIC}$, the main processes causing the nonconservative behaviour of DIC and TA can be further clarified (Cai et al., 2004; Li et al., 2017; Liu et al., 2014). Throughout the winter in the low water period, the rivers flowing into the JZB had no natural runoff and the salinity in the northeastern area of the JZB was always the lowest. Therefore,

400 the sewage discharge from the three wastewater treatment plants became the main source of 401 terrestrial input, and the impact ratio of $\Delta \mathrm{DIC}$ to $\Delta \mathrm{TA}$ was approximately 1.03:1 (Li et al., 2017). 402 For the production/respiration, the phytoplankton preferred $\mathrm{NH}_{4}-\mathrm{N}$ as a nitrogen source in the JZB 403 (Jiao, 1993). According to the Redfield equation with $\mathrm{NH}_{4}-\mathrm{N}$ as the nitrogen source (Redfield, 1963), 
the fixed ratio of $\Delta \mathrm{DIC}$ to $\Delta \mathrm{TA}$ altered by this process was $106: 15$. The fixed ratio of TA to DIC

405 altered by the $\mathrm{CaCO}_{3}$ process was $2: 1$, and $\mathrm{CO}_{2}$ evasion/invasion did not change TA while affected 406 DIC. Thus, the Figure 10 can be obtained.

407 The $\Delta \mathrm{TA} / \Delta \mathrm{DIC}$ values in December were all located in the first quadrant, between the ratio 408 lines of direct treated sewage input and aerobic respiration (Figure $10 \mathrm{a}, \mathrm{b}$ ). This indicated that the 409 DIC and TA additions were mainly caused by direct treated sewage input and aerobic respiration. 410 The total amount of daily treated sewage from the three wastewater treatment plants near the 411 northeastern area was 510,000 tons, and the DIC and TA concentrations of discharged sewage were 412 as high as $2554 \sim 5173 \mu \mathrm{mol} / \mathrm{kg}$ and $2326 \sim 4570 \mu \mathrm{mol} / \mathrm{kg}$, respectively. Obviously, the direct input 413 of sewage was an important factor for the addition of DIC and TA in the northeastern area (Liu et 414 al., 2019; Yang et al., 2018). The impact of sewage on aquatic environment has been widely reported 415 in China (Yang et al., 2008; Yang et al., 2012). Meanwhile, the DO in the entire bay was unsaturated, 416 and the $\mathrm{DO} \%$ was the lowest in the northeastern area with the highest $p \mathrm{CO}_{2}$, which confirmed the 417 existence of an aerobic respiration process. Moreover, since aerobic respiration had little effect on 418 TA while increased DIC according the Redfield ratio, $\Delta \mathrm{DIC}$ values were obviously larger than $\Delta \mathrm{TA}$ 419 values in December. In addition, the influence of perennial urbanization and long water residence 420 time ( $\sim 60$ days, Liu et al., 2004) allowed the northeastern area of the bay to accumulate large 421 amounts of terrestrial materials (high DIC and TA input, organic matter, and others). Under the 422 strong vertical mixing in winter, the upwelling of bottom water would increase the DIC and TA in 423 surface seawater, and the organic matter carried from bottom would further promote aerobic 424 respiration and increase DIC.

425 After identifying that the main non-temperature processes which caused DIC and TA addition 426 in December were treated sewage input and aerobic respiration, the DIC/TA value was introduced 427 to explain their impacts on $p \mathrm{CO}_{2}$. The DIC/TA value can directly indicate the relative abundance of 428 carbonate species (e.g., $\mathrm{HCO}_{3}{ }^{-}$and $\mathrm{CO}_{3}{ }^{-}$) in seawater. As such, for a specific temperature and 429 pressure, seawater surface $p \mathrm{CO}_{2}$ is correlated with this ratio (Wang et al., 2013). The DIC/TA value 430 of treated sewage (1.03) was higher than that of the seawater (0.92 0.97) in the JZB. Therefore, 431 direct treated sewage input could increase the DIC/TA and $p \mathrm{CO}_{2}$ of seawater in the northeastern 
area. Meanwhile, aerobic respiration increased DIC by producing $\mathrm{CO}_{2}$ directly and had a stronger increase effect on DIC/TA and $p \mathrm{CO}_{2}$. The significant negative correlation between the $\mathrm{n} p \mathrm{CO}_{2}$ (the temperature effect was removed) and DO\% $(p<0.05)$ (Figure 11a) indicated that aerobic respiration had a dramatic effect on $p \mathrm{CO}_{2}$ in the entire bay and it caused the bay to act as a $\mathrm{CO}_{2}$ source in December. In the northeastern area with the lowest salinity, the degree of DO unsaturation was largest and the effects of treated sewage input were superimposed, so the $p \mathrm{CO}_{2}$ was highest. As the sea area extended to the mouth area, the degree of DO unsaturation decreased gradually. The decline of aerobic respiration caused a gradual decrease in $p \mathrm{CO}_{2}$ (Figure 11b). The dominant of aerobic respiration in December may be related to that the strengthened vertical mixing brought organic matters and the moderate temperature favoured the degradation activity of heterotrophic bacteria. The similar phenomenon was reported in the continental shelf off Georgia (USA) and the northern Yellow Sea (Jiang et al., 2010; Xu et al., 2016).

\subsection{Primary production promoted the strength of $\mathrm{CO}_{2} \operatorname{sink}$ in winter}

The distributions of $\Delta \mathrm{TA} / \Delta \mathrm{DIC}$ in the four cruises from early January to late February are shown in Figure 10c-f. In the northeastern area in early January, $\Delta \mathrm{TA} / \Delta \mathrm{DIC}$ values were similar to those in December, between the ratio lines of aerobic respiration and treated sewage input. This suggested that the DIC additions in this area were still mainly caused by these two processes. However, in the western area in early January and the entire bay in mid-January, all $\Delta \mathrm{TA} / \Delta \mathrm{DIC}$ values were larger than 0.97 (the ratio of the treated sewage-altered $\Delta \mathrm{TA}$ and $\Delta \mathrm{DIC}$ ), moving toward the ratio line of primary production. Considering the oversaturated DO in these periods and regions, the data indicated that primary production obviously consumed DIC, while the treated sewage input directly added DIC and TA. It is worth noting that the $\Delta \mathrm{TA} / \Delta \mathrm{DIC}$ in these periods and regions were also close to the ratio lines of $\mathrm{CaCO}_{3}$ dissolution and $\mathrm{CO}_{2}$ evasion. This resulted from the coupled effects of direct treated sewage input and primary production because the possibility of $\mathrm{CaCO}_{3}$ dissolution and $\mathrm{CO}_{2}$ evasion were very low based on the high $\Omega_{\text {arag }} @$ situ ( $\left.>1.80\right)$ and appearance of a $\mathrm{CO}_{2}$ sink (Figures 4,12 ). In late January and late February, the degree of DO oversaturation was higher and the $\Delta \mathrm{TA} / \Delta \mathrm{DIC}$ values were closer to the ratio line of primary production, indicating the stronger consumption of DIC from primary production. 
461 in December to primary production during January and February, which caused an obvious decrease in $p \mathrm{CO}_{2}$ in the JZB (Figure 4). In the northeastern area of the JZB in early January, DO remained unsaturated and aerobic respiration dominated and the region still acted as a $\mathrm{CO}_{2}$ source. However, in the western area in early January and the entire bay during mid-January, late January and late February, DO was oversaturated and primary production dominated. The good correlations of n $p \mathrm{CO}_{2}$ vs. $\mathrm{DO} \%$ and $\mathrm{Chl} a$ vs. DO\% (Figure 13) indicated that absorption of $\mathrm{CO}_{2}$ by primary

467 production played an important role in the performance of the $\mathrm{CO}_{2}$ sink in these periods and regions.

468 In the western area in early January, the DO was slightly oversaturated, and the primary production 469 began to dominate and turned the sea area from a $\mathrm{CO}_{2}$ source in December into a sink. From mid470 January to late January, both DO supersaturation and Chl $a$ concentration increased (Figure 5h), and 471 the correlation coefficients $\left(\mathrm{r}^{2}\right)$ of $\mathrm{n} p \mathrm{CO}_{2}$ vs. $\mathrm{DO} \%$ and $\mathrm{DO} \%$ vs. Chl $a$ also increased. The 472 enhancement of primary production continuously strengthened the $\mathrm{CO}_{2}$ sink in the period (Figure $4734 \mathrm{~h}$ ). In terms of the direct input of treated sewage, the increase in $p \mathrm{CO}_{2}$ caused by this process was 474 persistent. However, the $\mathrm{DO} \%$ was always the highest and the $p \mathrm{CO}_{2}$ was always the lowest in the 475 northeastern area from mid-January to late February (Figures 4, 5), indicating that strong $\mathrm{CO}_{2}$ 476 consumption from primary production covered the increase in $p \mathrm{CO}_{2}$ caused by direct input of treated 477 sewage.

478 The dominant of primary production in this period may be related to the relatively low 479 seawater temperature. The average seawater temperature had decreased obviously and was below $4804{ }^{\circ} \mathrm{C}$ since early January and even below $2{ }^{\circ} \mathrm{C}$ in late January, which suppressed the activities of 481 aerobic respiration. Meanwhile, under stable hydrologic conditions and nutrient accumulation in 482 winter, the cold algae community, which had strong photosynthetic activity and was acclimatized to 483 low temperatures, often exhibited a vigorous growth in the JZB in January and February (Li and 484 Sun, 2014; Sun et al., 2011a; Wu et al., 2004). This is also the reasons for the vigorous growth of 485 phytoplankton in the nearshore areas of Hokkaido (Japan) and Blanca (Argentina) (Popovich et al., 486 2008; Sakamoto et al., 2008). The weakening of feeding pressure caused by low temperatures may be another reason. In Narragansett Bay, Oviatt et al. (2002) noted that the feeding effect from 
zooplankton and filter feeders was inhibited and algal blooms usually occurred when the seawater temperature was below $3{ }^{\circ} \mathrm{C}$. In Massachusetts Bay, Keller et al. (2011) found a good negative correlation between average $\mathrm{Chl} a$ concentration and seawater temperature during winters from

4911995 to 1999 and they emphasized the control of zooplankton feeding on algal blooms.

\subsection{The coupled effects of primary production and $\mathrm{CaCO}_{3}$ precipitation on the $p \mathrm{CO}_{2}$ in $\mathrm{March}$}

In March, all $\Delta \mathrm{TA} / \Delta \mathrm{DIC}$ values fell in the third quadrant, basically between the ratio lines of primary production and $\mathrm{CaCO}_{3}$ precipitation (Figure 10g). Combined with oversaturated $\mathrm{DO}$ and high $\Omega_{\text {arag }}$ situ (2.28 2.53, Figure 12g), it could be inferred that the removal of DIC and TA was mainly caused by primary production and $\mathrm{CaCO}_{3}$ precipitation. Compared to late February, both the DO oversaturation and the Chl $a$ concentration decreased obviously in this period (Figure 5h). Thus,

498 the weakening of primary production was an important factor causing the increase in $p \mathrm{CO}_{2}$ in March. 499 Meanwhile, $\mathrm{n} p \mathrm{CO}_{2}$ showed no correlation with DO\% (Figure 14a), indicating the reduced influence 500 of primary production on the spatial distribution of $p \mathrm{CO}_{2}$. In terms of $\mathrm{CaCO}_{3}$ precipitation, this process consumed twice TA of DIC, and it further increased the $p \mathrm{CO}_{2}$ levels in March. Considering

502 that primary production consumed DIC but hardly affected TA, the degree of TA removal $(\Delta \mathrm{TA})$ 503 could indicate the strength of $\mathrm{CaCO}_{3}$ precipitation in the period. As shown in Figure $14 \mathrm{~b}, \mathrm{n} p \mathrm{CO}_{2}$ was the highest in the northern area, where the TA removal was the largest $(\sim-25 \mu \mathrm{mok} / \mathrm{kg})$. As the sea area extended to the mouth area, TA removal and $p \mathrm{CO}_{2}$ showed a decreasing trend. Obviously, the release of $\mathrm{CO}_{2}$ from $\mathrm{CaCO}_{3}$ precipitation had a certain influence on the spatial distribution of $p \mathrm{CO}_{2}$ in March. Despite this, the losses of DIC and TA in March were all $<30 \mu \mathrm{mol} / \mathrm{kg}$, indicating the small intensity of primary production and $\mathrm{CaCO}_{3}$ precipitation. Moreover, due to the opposite

509 effects on $p \mathrm{CO}_{2}$ from the above two processes, the $\mathrm{n} \mathrm{CO}_{2}$ differences between the stations in this 510 period were small, less than $30 \mu \mathrm{atm}$. In summary, in March, primary production and $\mathrm{CaCO}_{3}$ 511 precipitation together affected the concentration and spatial distribution of $p \mathrm{CO}_{2}$ in the JZB.

512 The primary production may be constrained by the insufficient supply of nutrients in the bay 513 in March. According to the observation between 2004 and 2008 (Sun et al., 2011b), the nutrient 514 concentration in the JZB showed a gradual decrease from December to March and reached the minimum of $<0.2 \mathrm{mg} / \mathrm{L}$ in March. Meanwhile, the increase of feeding pressure caused by higher 
seawater temperature also reduced the phytoplankton biomass (Zhang et al., 2005). The appearance

517 of $\mathrm{CaCO}_{3}$ precipitation in March may be related to the previously strong primary production in

518 January and February. This is because large amounts of $\mathrm{CO}_{2}$ consumption from primary production

519 can increase the concentration of $\mathrm{CO}_{3}{ }^{2-}$ and promote the rise of $\Omega_{\text {arag, }}$, which could increase the

520 possibility of $\mathrm{CaCO}_{3}$ precipitation (Kim et al., 2013; Xue et al., 2017). Meanwhile, the seawater

521 temperature rose, and clams began to grow in spring (Zhang et al., 2005). The northern area of the

522 JZB, where TA removal is the greatest, is an important breeding area for shellfish (Ruditapes

523 philippinarum) in Qingdao, indicating that the appearance of $\mathrm{CaCO}_{3}$ precipitation may be associated

524 with human shellfish farming activities.

525 In summary, from aerobic respiration in December to primary production during January and

526 February, and then to the weaken of primary production and the presence of $\mathrm{CaCO}_{3}$ precipitation in

527 March, the transition of non-temperature processes changed the JZB from a $\mathrm{CO}_{2}$ source to sink and

528 then to a weak sink throughout the winter. At the same time, the water temperature gradually

529 decreased from December to late January and then increased until March, which suggested that the

530 direction of temperature effect on $p \mathrm{CO}_{2}$ was consistent with the non-temperature effect in most

531 periods and temperature variation further expanded the $p \mathrm{CO}_{2}$ variation range. Finally, according to

532 the climatological mean wind speed in Qingdao from December to March (5.6 m/s, Yuan et al., 1996)

533 and the average atmospheric $\mathrm{CO}_{2}$ concentration $(408 \mu \mathrm{atm})$ in the Tae-ahn Peninsula station from

534 December 2015 to March 2016, the gas transfer velocity formula of Sweeney et al. (2007) was used

535 to calculate the sea-air exchange fluxes of $\mathrm{CO}_{2}\left(\mathrm{FCO}_{2}\right)$. Overall, the JZB appeared as a sink of

536 atmospheric $\mathrm{CO}_{2}$ throughout the winter, with the average $\mathrm{FCO}_{2}$ of $-3.8 \mathrm{mmol} \mathrm{m}{ }^{-2} \mathrm{~d}^{-1}$. In December,

537 the average $\mathrm{FCO}_{2}$ of the two cruises was $3.0 \mathrm{mmol} \mathrm{m}^{-2} \mathrm{~d}^{-1}$. Then the bay turned into an atmospheric

$538 \mathrm{CO}_{2}$ sink and the strength of sink continued to increase, from $-6.4 \mathrm{mmol} \mathrm{m}^{-2} \mathrm{~d}^{-1}$ in early January to

$539-15.5 \mathrm{mmol} \mathrm{m}^{-2} \mathrm{~d}^{-1}$ in late February. In March, the sink strength decreased obviously and the $\mathrm{FCO}_{2}$

540 came to $-1.1 \mathrm{mmol} \mathrm{m}^{-2} \mathrm{~d}^{-1}$.

\section{$541 \quad$ 5. Conclusions}

542 In the JZB from December to March, the mutual effect of non-temperature processes among 543 aerobic respiration, primary production and $\mathrm{CaCO}_{3}$ precipitation were the main intrinsic driving 
544 forces for the $p \mathrm{CO}_{2}$ variation. Meanwhile, the direction of temperature effect on $p \mathrm{CO}_{2}$ was

545 consistent with the non-temperature effect in most periods. In December, the higher seawater 546 temperature and the dominance of respiration resulted in the bay acting as a $\mathrm{CO}_{2}$ source. From early

547 January to late January, with the decrease in $p \mathrm{CO}_{2}$ caused by cooling, primary production of cold 548 algae increased obviously and the $\mathrm{Chl} a$ concentration peaked in late February, with the consequence 549 that the JZB became a larger $\mathrm{CO}_{2}$ sink. In March, the seawater temperature rose, and the strength of $550 \mathrm{CO}_{2}$ sink weakened obviously. In this period, with the decrease of primary production, the release 551 of $\mathrm{CO}_{2}$ from $\mathrm{CaCO}_{3}$ precipitation appeared. The offsetting of these two processes resulted in a minor 552 difference of the distribution of $p \mathrm{CO}_{2}$. The strong biogeochemical process occurred widely in the 553 mid-latitude coasts in winter, and its marked impact on seawater $p \mathrm{CO}_{2}$ should not be ignored. To 554 further improve our understanding of $\mathrm{CO}_{2}$ sink/source change process and the influence factors in 555 coastal waters, more field studies are still largely needed.

\section{Acknowledgements}

557 This work was supported by the National Natural Science Foundation of China (NSFC) (Grant 558 No. 41376123), the National Natural Science Foundation of China - Shandong Joint Fund for 559 Marine Science Research Centres (NSFC) (Grant No. U1406403) and the Science and Technology 560 Foundation of Shanxi Agricultural University (Grant No. 2018YJ21). We thank Qianqian Jiang, 561 Xiangyu Liu and Ping Han for the sampling and measuring work.

\section{References}

563 Bauer J E, et al, 2013. The changing carbon cycle of the coastal ocean. Nature, 504, 61-70.

564 Bianchi A A, et al, 2009. Annual balance and seasonal variability of sea-air $\mathrm{CO}_{2}$ fluxes in the

Borges A V, 2011. Present day carbon dioxide fluxes in the coastal ocean and possible feedbacks under global change. Oceans and the Atmospheric Carbon Content, 47-77.

Bozec Y, et al, 2012. Seasonal dynamics of air-sea $\mathrm{CO}_{2}$ fluxes in the inner and outer Loire estuary

571 Cai W J, et al, 2004. The biogeochemistry of inorganic carbon and nutrients in the Pearl River 

1319.

Cai W J, et al, 2008. A comparative overview of weathering intensity and $\mathrm{HCO}_{3}{ }^{-}$flux in the world's major rivers with emphasis on the Changjiang, Huanghe, Zhujiang (Pearl) and Mississippi rivers. Continental Shelf Research, 28(12), 1538-1549.

Cai W J, 2011. Estuarine and coastal ocean carbon paradox: $\mathrm{CO}_{2}$ sinks or sites of terrestrial carbon incineration? Annual Review of Marine Science, 3(3), 123-145.

Chen C, et al, 1999. Influences of physical processes on the ecosystem in Jiaozhou Bay: a coupled physical and biological model experiment. Journal of Geophysical Research Oceans, 104, 29925-29949.

Chen C-T A, et al, 2013. Air-sea exchanges of $\mathrm{CO}_{2}$ in the world's coastal seas. Biogeosciences, 10, 6509-6544.

Cohen J E, et al, 1997. Estimates of coastal populations, Science, 278, 1209-1213.

de la Paz M, et al, 2009. Surface $\mathrm{fCO}_{2}$ variability in the Loire plume and adjacent shelf waters: High spatio-temporal resolution study using ships of opportunity. Marine Chemistry, 71(1), 55-64.

Dickson A G and Millero F J, 1987. A comparison of the equilibrium constants for the dissociation of carbonic acid in seawater media. Deep Sea Research Part A Oceanographic Research Papers, 34(10), 1733-1743.

Gao Z, et al, 2008. The land-sourced pollution in the Jiaozhou Bay. Chinese Journal of Oceanology

593 Guillaud J F, et al, 2008. Seasonal variation of riverine nutrient inputs in the northern Bay of Biscay 594 (France), and patterns of marine phytoplankton response. Journal of Marine Systems, 72(1-4), 309-319.

Heike L, et al, 2004. The $p \mathrm{CO}_{2}$ variability in the midlatitude North Atlantic Ocean during a full annual cycle. Global Biogeochemical Cycles, 18, GB3023.

598 Jiang L Q, et al, 2010. Pelagic community respiration on the continental shelf off Georgia, USA. Biogeochemistry, 98(1), 101-113. 
600 Jiang L Q et al, 2013. Influence of terrestrial inputs on continental shelf carbon dioxide.

$601 \quad$ Biogeosciences, 10(2), 839-849.

602 Jiao N, 1993. Interactions between ammonium uptake and nitrate uptake by natural phytoplankton

603 assemblages. Chinese Journal of Oceanology and Limnology, 11(2), 97-107.

604 Keller A A, et al, 2011. Phytoplankton production patterns in Massachusetts Bay and the absence of 605 the 1998 winter-spring bloom. Marine Biology, 138(5), 1051-1062.

606 Kim D, et al, 2013. Biologically mediated seasonality of aragonite saturation states in Jinhae Bay, $607 \quad$ Korea. Journal of Coastal Research, 29(6), 1420-1426.

608 Laruelle G G, et al, 2014. Regionalized global budget of the $\mathrm{CO}_{2}$ exchange at the air-water interface 609 in continental shelf seas. Global Biogeochemical Cycles, 28, 1199-1214.

610 Lewis E and Wallace D W R, 1998. Program developed for $\mathrm{CO}_{2}$ systems calculations. 611 ORNL/CDIAC 105, Carbon Dioxide Information Analysis Center, Oak Ridge National 612 Laboratory US Department of Energy, Oak Ridge, Tennessee.

613 Li J L and Sun X X, 2014. Photosynthetic characteristics of phytoplankton in winter in the Jiaozhou 614 Bay. Oceanologia et Limnologia Sinica, 3(45), 468-479. (in Chinese).

615 Li N, et al, 2006. Natural environment and geological evolution of Jiaozhou Bay. Ocean Press, 616 Beijing (in Chinese).

617 Li X, et al, 2007. Role of the Jiaozhon Bay as a source/sink of $\mathrm{CO}_{2}$ over a seasonal cycle. Scientia $618 \quad$ Marina, 71(3), 441-450.

619 Li Y, et al, 2017. Controlling mechanisms of surface partial pressure of $\mathrm{CO}_{2}$ in Jiaozhou Bay during 620 summer and the influence of heavy rain. Journal of Marine Systems, 173, 49-59.

621 Liu Z, et al, 2004. Simulation of water exchange in Jiaozhou Bay by average residence time 622 approach. Estuarine Coastal and Shelf Science, 61(1), 25-35

Liu Z, et al, 2014. Removal of dissolved inorganic carbon in the Yellow River Estuary. Limnology and Oceanography, 59(2), 413-426.

Liu X Y, et al, 2019. Variations in dissolved inorganic carbon species in effluents from large-scale municipal wastewater treatment plants (Qingdao, China) and their potential impacts on coastal acidification. Environmental Science and Pollution Research, 26, 15019-15027. 
Ljubimir S, et al, 2017. Interannual (2009-2013) variability of winter-spring phytoplankton in South Adriatic Sea: effects of deep convection and lateral advection. Continental Shelf Research, 143, 311-321.

Mehrbach C, et al, 1973. Measurement of the apparent dissociation constants of carbonic acid in seawater at atmospheric pressure. Limnology and Oceanography, 18(18), 897-907.

Millero F J, 1979. The thermodynamics of the carbonate system in seawater. Geochimica Et Cosmochimica Acta, 43(10), 1651-1661.

Miyazawa Y, et al, 2017. Assimilation of high-resolution sea surface temperature data into an operational nowcast/forecast system around Japan using a multi-scale three-dimensional variational scheme. Ocean Dynamics, 67(6), 713-728.

Mucci A, 1983. The solubility of calcite and aragonite in seawater at various salinities, temperatures, and one atmosphere total pressure. American Journal of Science, 283(7), 14-27.

Nakaoka S I, et al, 2006. Temporal and spatial variations of oceanic $p \mathrm{CO}_{2}$ and air-sea $\mathrm{CO}_{2}$ flux in the Greenland Sea and the Barents Sea. Tellus 58B, 148-161.

Oviatt C, et al, 2002. Annual primary production in Narragansett Bay with no bay-wide winterspring phytoplankton bloom. Estuarine Coastal and Shelf Science, 54(6), 1013-1026.

Popovich C A, et al, 2008. Dissolved nutrient availability during winter diatom bloom in a turbid and shallow estuary (Bahía Blanca, Argentina). Journal of Coastal Research, 24(1), 95-102.

Redfield A C, 1963. The influence of organisms on the composition of seawater. In: Hill, M.N. (Ed.), The Sea. vol. 2. Interscience, pp. 26-77.

Ribas-Ribas M, et al, 2011. Air-sea $\mathrm{CO}_{2}$ fluxes in the north-eastern shelf of the Gulf of Cádiz (southwest Iberian Peninsula). Marine Chemistry, 123(1-4), 56-66.

Sakamoto A, et al, 2008. Time series of carbonate system variables off Otaru coast in Hokkaido, Japan. Estuarine Coastal and Shelf Science, 79(3), 377-386.

Sun X, et al, 2011a. Long- term changes of chlorophyll a concentration and primary productivity in the Jiaozhou Bay. Oceanologia et Limnologia Sinica, 42(5), 654-661. (in Chinese).

Sun X, et al, 2011b. Long- term changes in nutrient concentration and structure in the Jiaozhou Bay. Oceanologia et Limnologia Sinica, 42(5), 662-669. (in Chinese). 
Sweeney C, et al, 2007. Constraining global air-sea gas exchange for $\mathrm{CO}_{2}$ with recent bomb ${ }^{14} \mathrm{C}$ measurements. Global Biogeochemical Cycles, 21, GB2015.

Takahashi T, et al, 1993. Seasonal variation of $\mathrm{CO}_{2}$ and nutrients in the high-latitude surface oceans: a comparative study. Global Biogeochemical Cycles, 7(4), 843-878.

Takahashi T, et al, 2002. Global sea-air $\mathrm{CO}_{2}$ flux based on climatological surface ocean $p \mathrm{CO}_{2}$ and seasonal biological and temperature effects. Deep Sea Research Part II: Topical Studies in Oceanography, 49(9-10), 1601-1622.

Tin H C, et al, 2016. Satellite-derived estimates of primary production during the Sargasso Sea winter/spring bloom: Integration of in-situ time-series data and ocean color remote sensing

Thomas $\mathrm{H}$, et al, 2005. Controls of the surface water partial pressure of $\mathrm{CO}_{2}$ in the North Sea.

$$
\text { Biogeosciences, 2(4), 323-334. }
$$

Wang B and Wang Z, 2011. Long-term variations in chlorophyll a and primary productivity in Jiaozhou Bay, China. Journal of Marine Biology, 1-6.

Wang Y J, et al, 2015. Temporal and spatial variations of chlorophyll a and environmental factors in Jiaozhou Bay in 2010-2011. Acta Oceanologica Sinica, 37 (4), 103-116 (in Chinese).

Wang Z A, et al, 2013. The marine inorganic carbon system along the Gulf of Mexico and Atlantic coasts of the United States: Insights from a transregional coastal carbon study. Limnology and

Wesslander $\mathrm{K}$, et al, 2010. Inter-annual variation of the air-sea $\mathrm{CO}_{2}$ balance in the southern Baltic Sea and the Kattegat. Continental Shelf Research, 30, 1511-1521.

Wu Y, et al, 2004. Quantitative study in long-term variation of phytoplankton in Jiaozhou Bay. $681 \mathrm{Xu} \mathrm{X}$, et al, 2016. Monthly $\mathrm{CO}_{2}$ at A4HDYD station in a productive shallow marginal sea (Yellow 682 Sea) with a seasonal thermocline: Controlling processes. Journal of Marine Systems, 159, 89683 99. 
684 Xue L, et al, 2012. Surface partial pressure of $\mathrm{CO}_{2}$, and air-sea exchange in the northern Yellow Sea. Journal of Marine Systems, 105-108(12), 194-206.

686 Xue L, et al, 2017. Sea surface aragonite saturation state variations and control mechanisms at the Gray’s Reef time-series site off Georgia, USA (2006-2007). Marine Chemistry, 195, 27-40.

Yang H, et al., 2008. Carbon source/sink function of a subtropical, eutrophic lake determined from an overall mass balance and a gas exchange and carbon burial balance. Environmental Pollution, 151, 559-568.

691 Yang H, et al., 2012. Pollution in the Yangtze. Science, 337, 410.

692 Yang W, et al, 2007. Preliminary study on effects of scallop cultivation on water quality in Jiaozhou Bay. Transactions of Oceanology and Limnology, (2), 86-93 (in Chinese).

694 Yang X, et al, 2018. Treated wastewater changes the export of dissolved inorganic carbon and its isotopic composition and leads to acidification in coastal oceans. Environmental Science and

Zang $\mathrm{H}$, et al, 2018. The contribution of low temperature and biological activities to the $\mathrm{CO}_{2}$ sink in Jiaozhou Bay during winter. Journal of Marine Systems, 186, 37-46.

Zhang $\mathrm{J} \mathrm{H}$, et al, 2005. Clearance rate, ingestion rate and absorption efficiency of cultivated clam ruditapes philippinarum in Jiaozhou Bay, China. Oceanologia et Limnologia Sinica, 36 (6), 548-555. (in Chinese)

Zhang $\mathrm{L}$, et al, 2012. Distribution and seasonal variation in the partial pressure of $\mathrm{CO}_{2}$ during autumn and winter in Jiaozhou Bay, a region of high urbanization. Marine Pollution Bulletin, 64(1), 56-65.

Zhai W, et al, 2015. Occurrence of aragonite corrosive water in the North Yellow Sea, near the Yalu River estuary, during a summer flood. Estuarine Coastal and Shelf Science, 166, 199-208. in the Bohai Sea. Marine Sciences, 28 (4), 34-39 (in Chinese). 


\section{Figure captions}

711 Figure 1. Study area and survey stations. Solid black circles represent the sampling stations and white stars represent wastewater treatment plants. The gray scale shows water depth.

713

714 Figure 2. Variations in seawater surface salinity and temperature during the seven cruises in the

715 JZB. The solid black and open blue squares represent the average seawater surface temperature and 716 salinity. The upper and lower error bars represent the maximum and minimum of seawater surface 717 temperature (salinity) in the cruise. The thick gray line represents the daily average seawater 718 temperature in the JZB from December to April during the period of 2008-2016. The daily seawater temperature data were from FRA-JCOPE2 reanalysis data in Japan

720 (http://www.jamstec.go.jp/jcope/htdocs/e/home.html) and were calculated using the JCOPE2 model 721 according to satellite data (for more method details, please refer to Miyazawa et al. (2017)).

723 Figure 3. Spatial distributions of seawater surface salinity and temperature during the seven cruises 724 in the JZB. The isoline represents salinity and the color scale shows temperature.

726 Figure 4. Spatial distributions of seawater surface $p \mathrm{CO}_{2}$ during the seven cruises in the JZB (a-g). 727 Mean $p \mathrm{CO}_{2}$ during the seven cruises and the upper and lower error bars represent the maximum and 728 minimum of $p \mathrm{CO}_{2}$ in each cruise (h).

730 Figure 5. Spatial distributions of seawater surface DO $\%$ and $\mathrm{Chl} a$ during the seven cruises in the 731 JZB (a-g). The isoline represents $\mathrm{Chl} a$ and the color scale shows DO\%. The mean DO\% and Chl $a$ 732 during the seven cruises and the upper and lower error bars represent the maximum and minimum 733 of DO\% (Chl $a)$ in each cruise (h).

735 Figure 6. Spatial distributions of seawater surface DIC and TA during the seven cruises in the JZB.

736 The isoline represents DIC and the color scale shows TA. 
738 Figure 7. Spatial distributions of $\triangle p \mathrm{CO}_{2}$ during the seven cruises in the JZB. $\Delta p \mathrm{CO}_{2}$ represents the 739 difference between $\mathrm{n} p \mathrm{CO}_{2}$ and in situ $p \mathrm{CO}_{2}$. The $\mathrm{n} p \mathrm{CO}_{2}$ represents the in situ $p \mathrm{CO}_{2}$ normalized to 740 the average seawater temperature for each cruise.

742 Figure 8. Variations in $p \mathrm{CO}_{2}$ (solid circle) and $\mathrm{N} \mathrm{CO}_{2}$ (open circle) during the seven cruises. $743 \quad \mathrm{~N} p \mathrm{CO}_{2}$ represents the average $p \mathrm{CO}_{2}$ for each cruise normalized to the average seawater temperature 744 of all seven cruises.

746 Figure 9. Scatterplot of $\triangle \mathrm{DIC}$ (red triangle) and $\Delta \mathrm{TA}$ (black circle) with salinity in the JZB during the seven cruises. $\Delta \mathrm{TA}$ and $\Delta \mathrm{DIC}$ are deviations calculated using Equations. 8 and 9.

Figure 10. Scatterplot of $\triangle \mathrm{TA}$ vs. $\triangle \mathrm{DIC}$ in the JZB during the seven cruises. The four lines represent 750 the theoretical ratio lines altered the $\triangle \mathrm{TA}$ and $\triangle \mathrm{DIC}$ by the direct treated sewage input, $\mathrm{CaCO}_{3}$ 751 precipitation/dissolution, biological process (primary production or respiration) and $\mathrm{CO}_{2}$ 752 evasion/invasion, respectively. The stations in northeastern area and western area were located in 753 the solid and dotted line circles in c, respectively. Color scale shows DO\%.

755 Figure 11. Scatterplot of $\mathrm{n} p \mathrm{CO}_{2}$ vs. DO\% (a) and DO\% vs. salinity (b) on 13 December (solid 756 circles, $\mathrm{y}_{1}$ ) and 21 December (open squares, $\mathrm{y}_{2}$ ).

758 Figure 12. Spatial distributions of seawater surface $\Omega_{\text {arag }} @$ situ during the seven cruises in the JZB. 759

760 Figure 13. Scatterplot of n $p \mathrm{CO}_{2}$ vs. DO\% (a) and DO \% vs. Chl $a$ (b) in western area in early January 761 (solid triangles, $\mathrm{y}_{1}$ ) and the entire bay in mid-January (open circles, $\mathrm{y}_{2}$ ), late January (solid squares, $\left.762 \mathrm{y}_{3}\right)$ and late February (stars, $\left.\mathrm{y}_{4}\right)$.

763

764 Figure 14. Scatterplot of $\mathrm{n} p \mathrm{CO}_{2}$ vs. $\mathrm{DO} \%$ (a) and $\mathrm{n} p \mathrm{CO}_{2}$ vs. $\Delta \mathrm{TA}$ (b). The open circles represent 765 the stations in northern area of the JZB. 
767 Table. 1. Summary of the sampling cruises. In late February, we only referenced the data covering 768 our research stations.

769

770 Table. 2. The values of salinity, DIC and TA of ocean end-member in each cruise during winter in 771 the JZB. 


\section{$772 \quad$ Figures}

\section{Figure 1.}

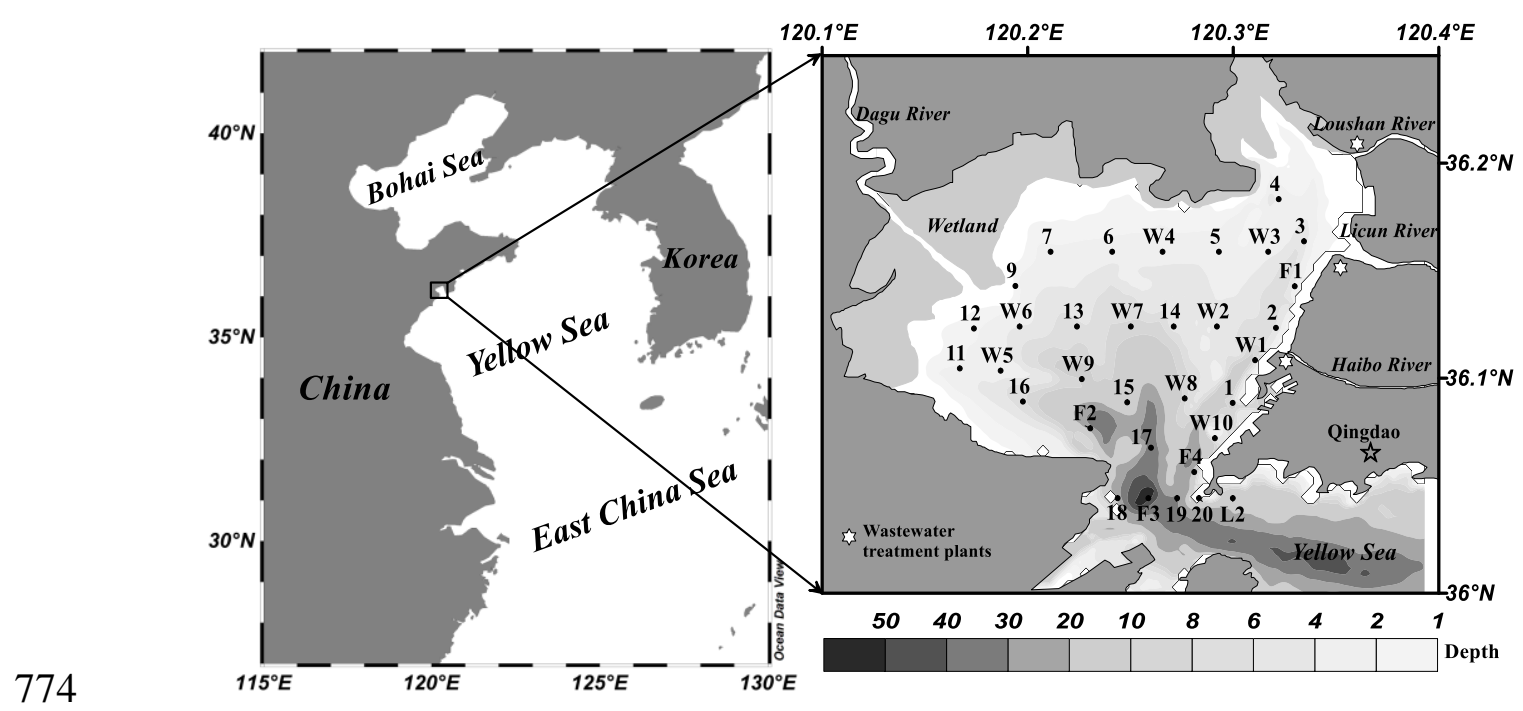


$775 \quad$ Figure 2.

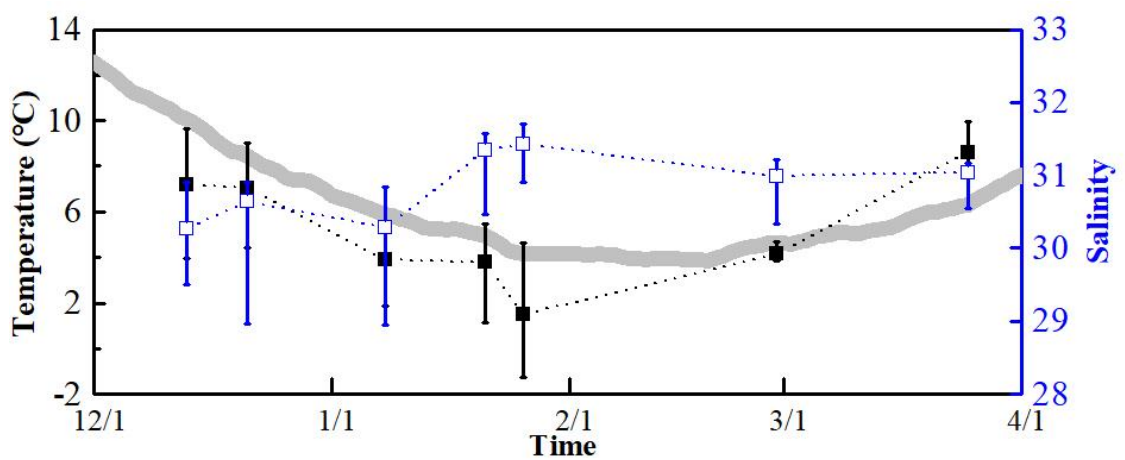

776

777 
$778 \quad$ Figure 3.

779

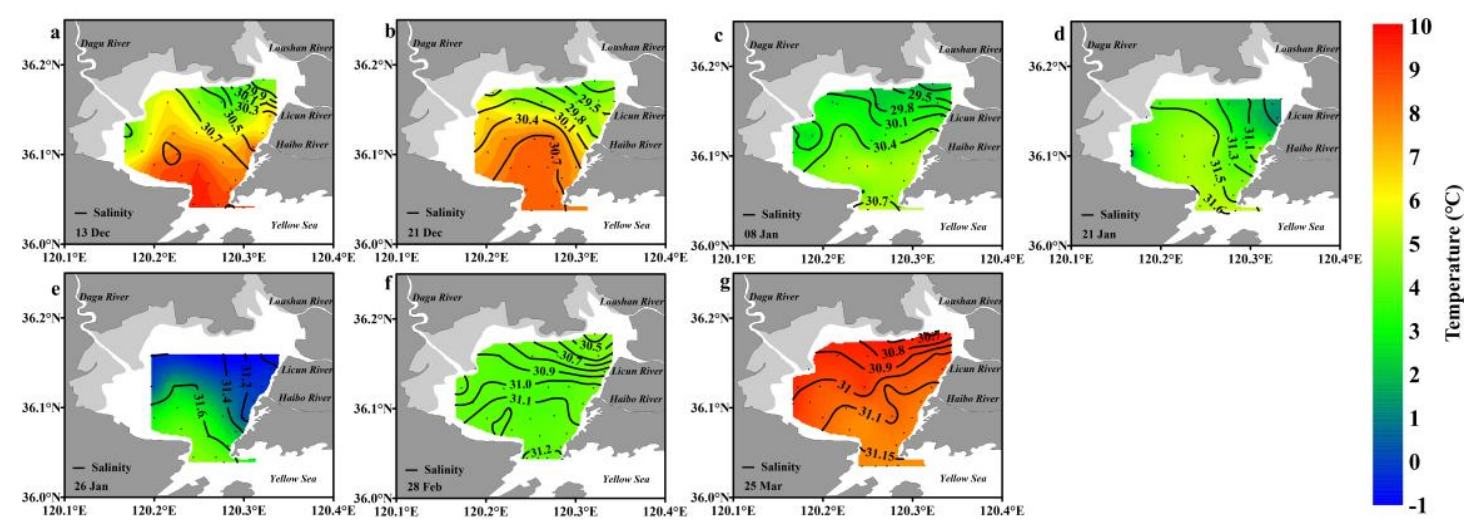

780 
$781 \quad$ Figure 4.

782

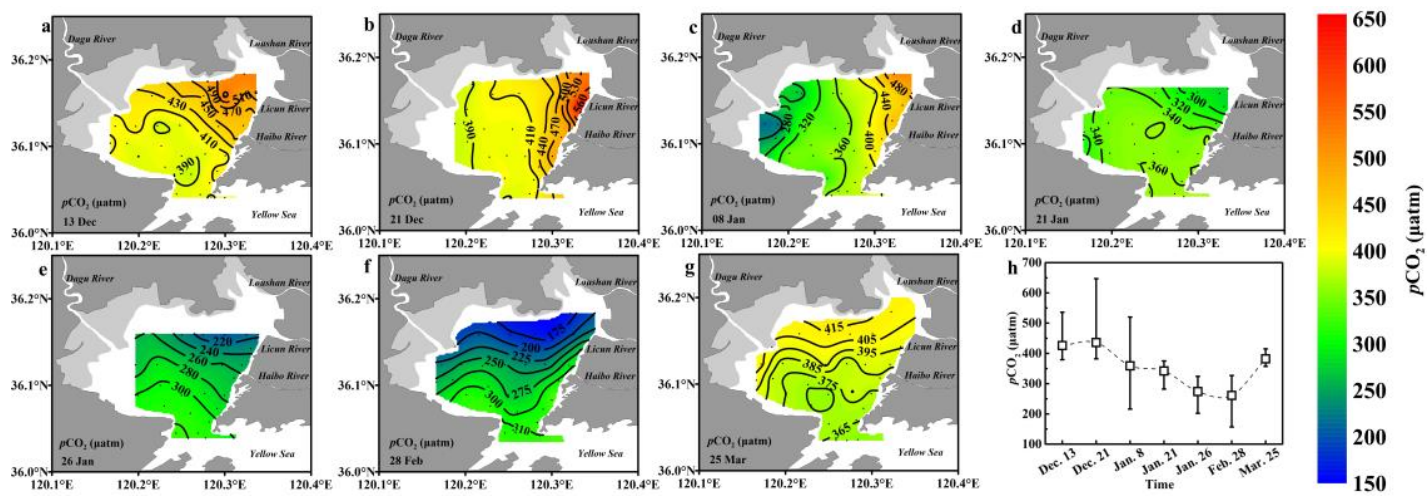

783 


\section{$784 \quad$ Figure 5.}

785
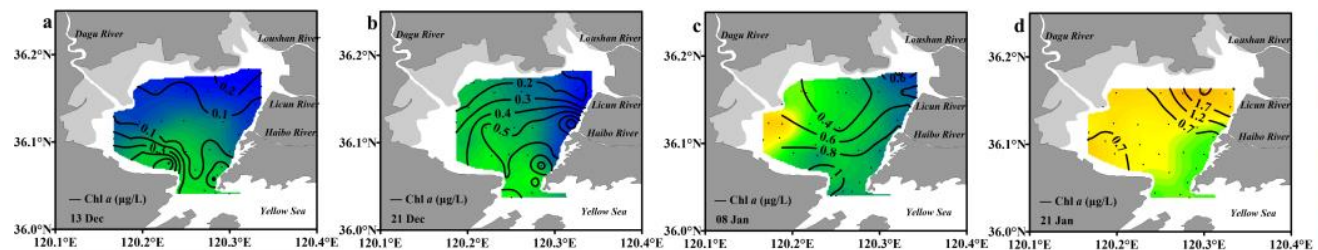

140
134

128

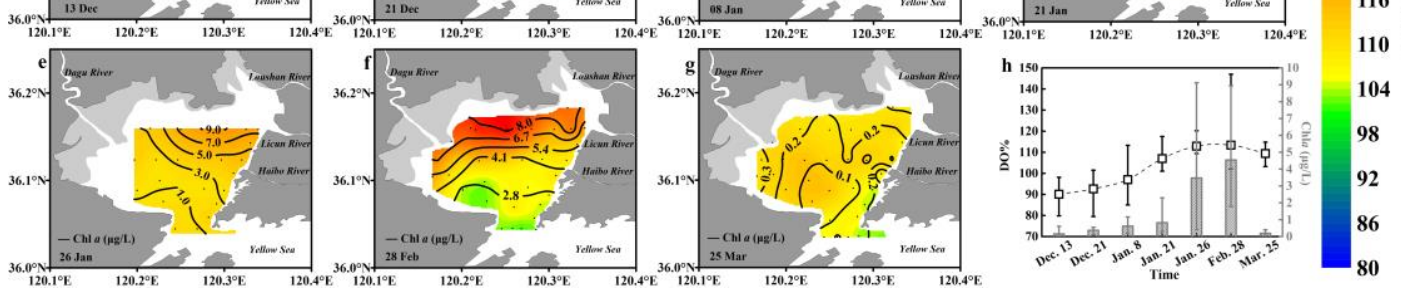

786 
$787 \quad$ Figure 6.

788
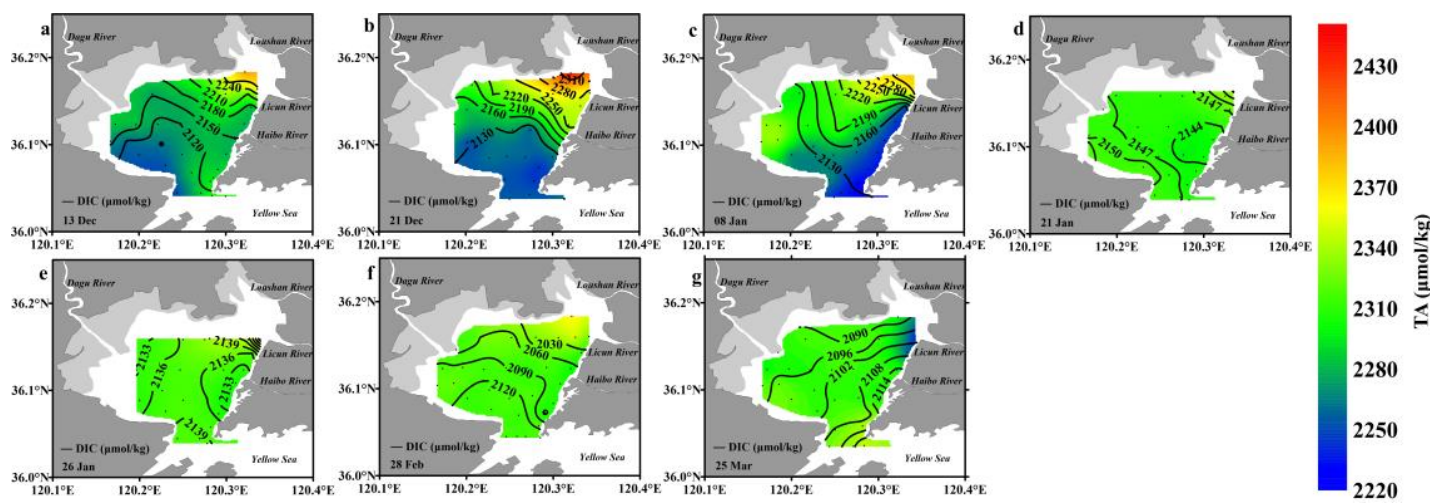

789 
$790 \quad$ Figure 7.

791
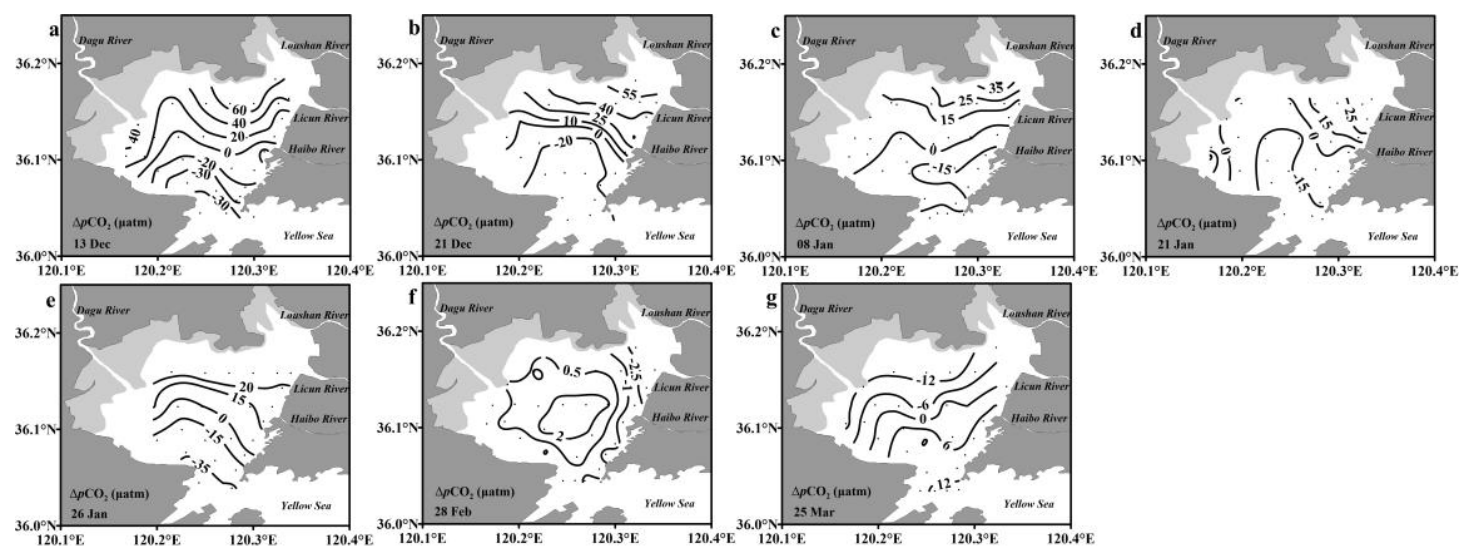

792 


\section{$793 \quad$ Figure 8.}

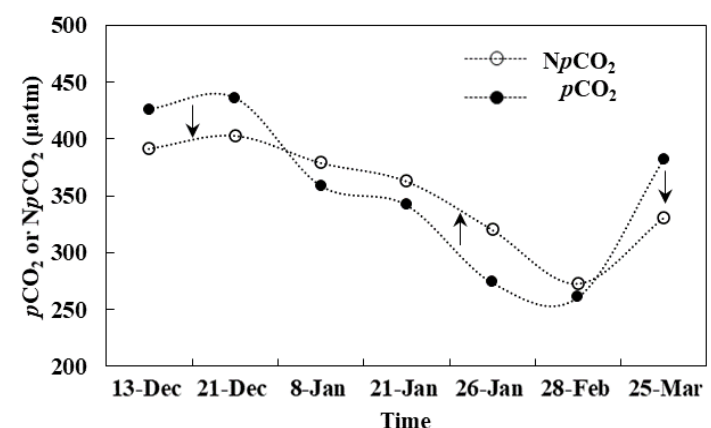

795 
$796 \quad$ Figure 9.
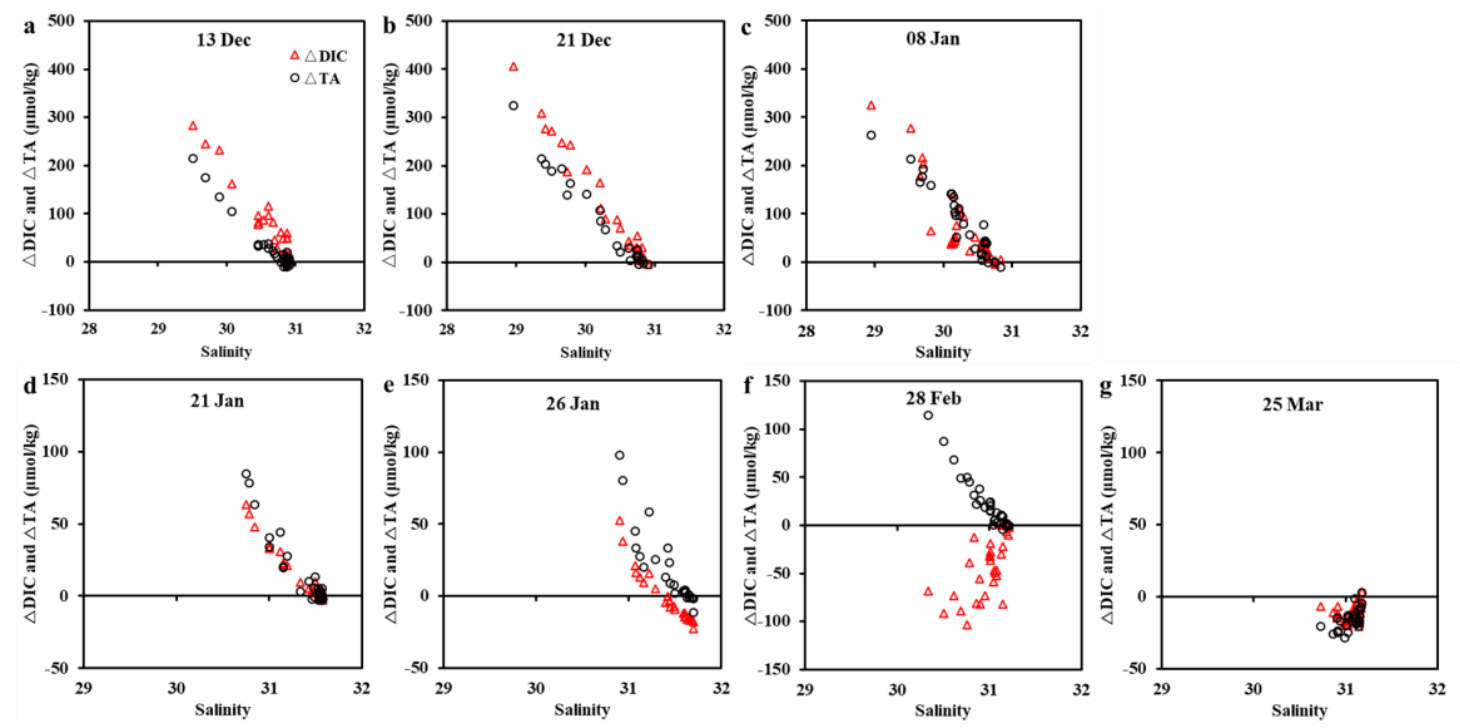


\section{Figure 10.}
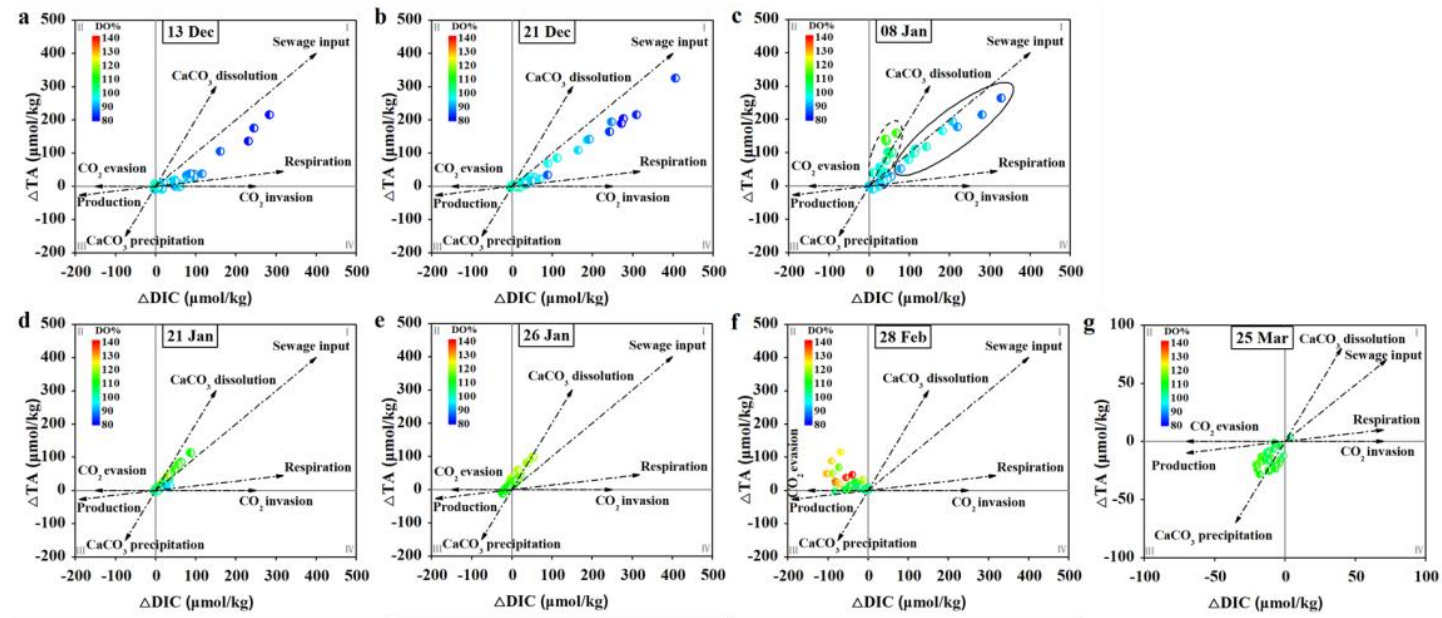

801 
Figure 11.
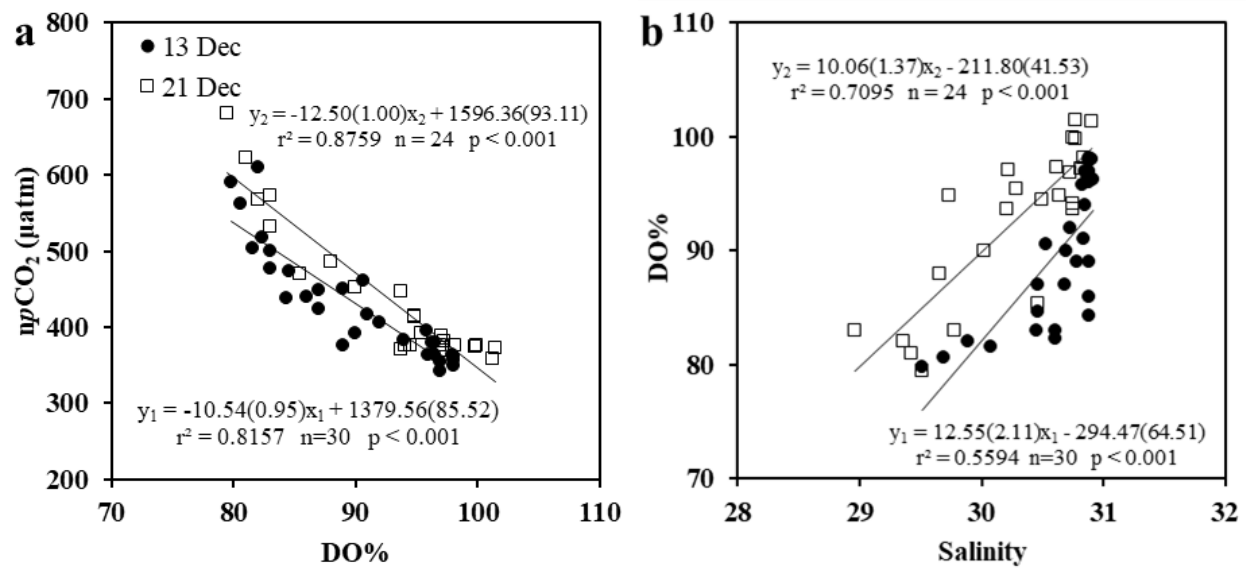

804 
805 Figure 12.

806
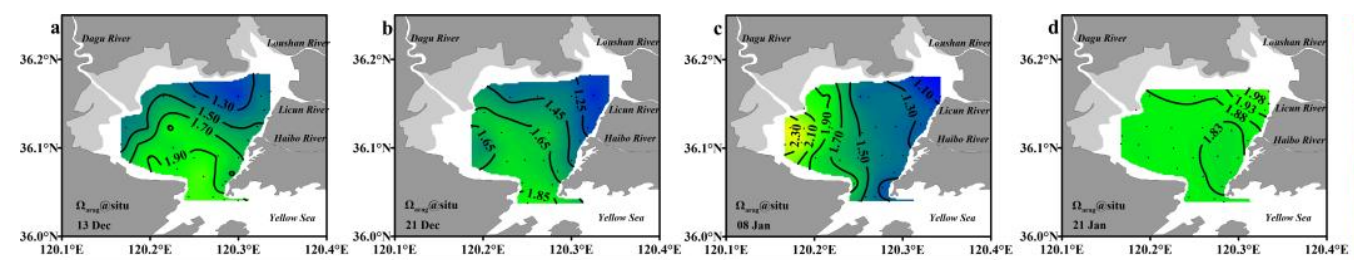

3.70

3.30

2.90

2.50 章
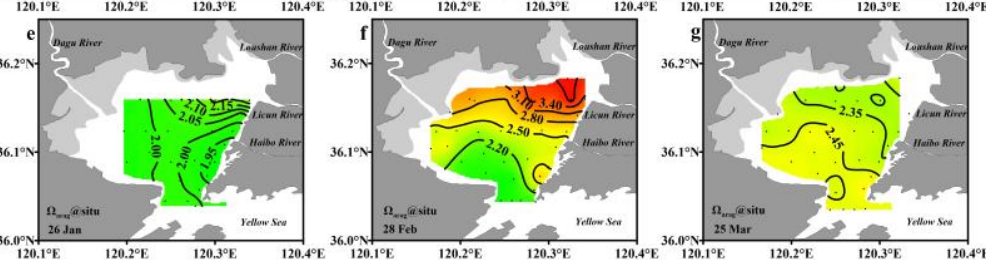

$2.10 \mathrm{C}^{\mathrm{s}}$

1.70

1.30

807 
Figure 13.

809
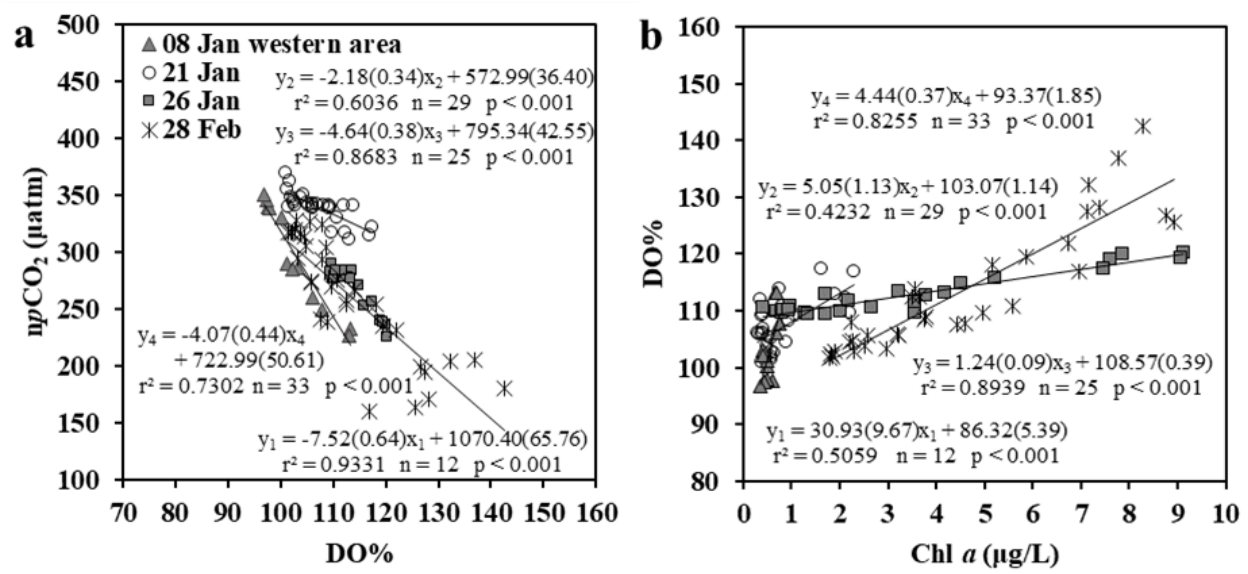

810 
$811 \quad$ Figure 14.
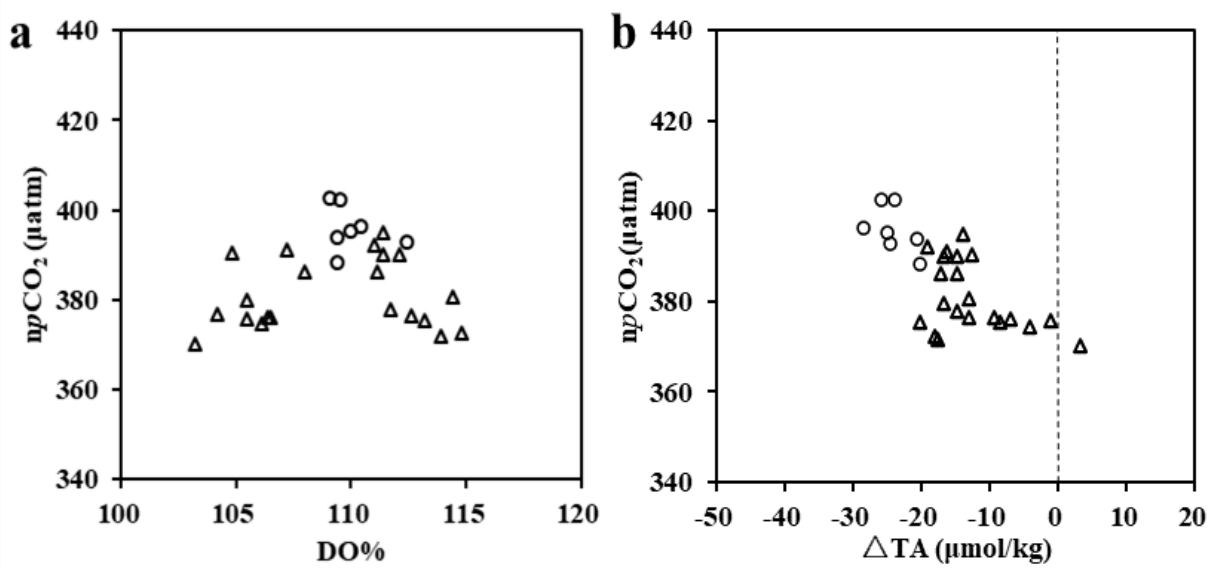

813 
Table. 1.

\begin{tabular}{cccc}
\hline Cruise & Surveying time & Number of stations & Reference/data source \\
\hline \multirow{2}{*}{ December } & 13 Dec. 2014 & 30 & This study \\
& 21 Dec. 2011 & 24 & This study \\
Early January & 08 Jan. 2012 & 33 & This study \\
Mid-January & 21 Jan. 2016 & 29 & Zang et al. (2018) \\
Late January & 26 Jan. 2016 & 25 & Zang et al. (2018) \\
Late February & 28 Feb. 2008 & 33 & Zhang et al. (2012) \\
March & 25 Mar. 2014 & 30 & This study \\
\hline
\end{tabular}

815 
816 Table. 2.

\begin{tabular}{cccc}
\hline Cruise & $\mathrm{S}_{\text {ocean }}$ & $\mathrm{DIC}_{\text {ocean }}$ & $\mathrm{TA}_{\text {ocean }}$ \\
\hline $13 \mathrm{Dec}$ & $30.88 \pm 0.00$ & $2102 \pm 2$ & $2277 \pm 1$ \\
$21 \mathrm{Dec}$ & $30.84 \pm 0.07$ & $2088 \pm 1$ & $2255 \pm 1$ \\
$08 \mathrm{Jan}$ & $30.75 \pm 0.00$ & $2117 \pm 4$ & $2240 \pm 0$ \\
$21,26 \mathrm{Jan}$ & $31.55 \pm 0.00$ & $2147 \pm 1$ & $2310 \pm 0$ \\
$28 \mathrm{Feb}$ & $31.21 \pm 0.00$ & $2140 \pm 2$ & $2314 \pm 1$ \\
$25 \mathrm{Mar}$ & $31.17 \pm 0.00$ & $2122 \pm 0$ & $2344 \pm 0$ \\
\hline
\end{tabular}

817 